\title{
Mechanical Properties of Alkali-Activated Concrete: A State-of-the-Art Review
}

\author{
Yao DING ${ }^{1}$, Jian-Guo DAI, ${ }^{2 *}$ and Cai-Jun $\mathrm{SHI}^{3}$
}

1. Ph.D. candidate, Department of Civil and Environmental Engineering, The Hong Kong Polytechnic University, Hong Kong, China.

2. Associate Professor (Corresponding author), Department of Civil and Environmental Engineering, The Hong Kong Polytechnic University, Hong Kong, China, Email: cejgdai@polyu.edu.hk.

3. Professor, College of Civil Engineering, Hunan University, Changsha, China 


\section{Abstract}

Alkali-activated concretes (AACs) are attracting increasing attention due to their potential as alternatives to ordinary Portland cement concrete (OPCC). This paper is a holistic review of current research on the mechanical properties of AAC including research on its compressive strength, tensile strength, elastic modulus, Poisson's ratio, stress-strain relationship under uniaxial compression, fracture properties, bond mechanism with steel reinforcement, dynamic mechanical properties, and high-temperature performance. Three types of AAC are reviewed: alkali-activated slag, alkali-activated fly ash, and alkali-activated slag-fly ash concretes. The applicability to AAC of design formulas found in codes of practice that were developed to estimate the basic mechanical performances of OPCC is also discussed. It is shown that, in general, AAC exhibits better bond performance with steel reinforcement and better strength performance after exposure to elevated temperatures than OPCC. For the other reviewed mechanical properties, the differences between AAC and OPCC largely depend on the proportions of raw materials in the concrete; specifically, the slag to fly ash ratio may be a very influential factor. As there is a trend to combine slag and fly ash in the production of AAC to achieve normal temperature curing and environmental friendliness, further research is deemed necessary to determine how the slag to fly ash ratio influences the fundamental mechanical properties of AAC and how this affects practical designs.

\section{Keywords}

Alkali-activated concrete; Slag; Fly ash; Static mechanical properties; Dynamic mechanical properties; High-temperature performance 


\section{Introduction}

Ordinary Portland cement concrete (OPCC) is the most widely used construction material in the world because it has numerous advantages such as flexible workability, high compressive strength, wide material availability, good fire resistance, easy maintenance, and low cost. However, the increasing emphasis on sustainable development has meant that the adverse environmental effects of ordinary Portland cement (OPC) production have been highlighted. The production of one ton of OPC consumes as much as 4 GJ of energy and emits nearly 0.85 ton of carbon dioxide into the atmosphere [1]. This has motivated researchers to explore new cementitious materials as partial or complete alternatives to OPC.

Partial replacement of OPC with industrial wastes such as fly ash (FA) or ground granulated blast furnace slag (GGBS) has been widely implemented. The replacement of cement with these industrial waste materials not only improves the environmental friendliness and sustainability of the concrete, it also improves the rheology, mechanical properties, and durability of the product. The mass replacement ratio of FA or other pozzolans to the total cementitious material is usually limited to about $15-25 \%[2,3]$, whereas for the GGBS, this ratio can be as high as $50-70 \%[4,5]$. Although some studies have explored the possibility of using higher replacement ratios of waste materials, a certain amount of OPC is always needed in the binders $[6$, 7].

Cement-free concrete has also been proposed. These concretes use industrial byproducts or natural aluminosilicate materials activated by an alkali activator to produce alkali-activated binders, which are then combined with fine and coarse aggregates and cured under proper conditions to form alkali-activated concrete (AAC) [8]. The carbon dioxide emissions produced in the production of alkali-activated cements are about $50-80 \%$ lower than in the production of OPC $[9,10]$. Within the broad group of alkali-activated binders, there are two main subclasses: high-calcium 
systems and low-calcium or calcium-free systems. Many researchers have demonstrated that the main hydration product of an alkali-activated slag-based binder, which is a typical high-calcium system, is $\mathrm{C}-\mathrm{S}-\mathrm{H}$ gel, which has a lower $\mathrm{Ca} / \mathrm{Si}$ ratio than traditional OPC $[11,12]$; in contrast, the main hydration product of low-calcium or calcium-free binders is N-A-S-H gel, which possesses a three-dimensional structure [13-16].

The physical and chemical properties of AAC depend largely on the raw materials used and the curing condition. It is generally recognized that AAC has better resistance to acid attack, sulfate attack, and chloride penetration [17]. In prior studies it was found that the drying and autogenous shrinkage of alkali-activated slag concrete (AASC) is more serious than that of OPC [17-20, 62]. The shrinkage is mainly influenced by the type of alkali activator, curing condition and alkali concentration and can be alleviated to some extent by adding shrinkage-reducing admixtures [18, 19] or fibers into the matrix [20-22]. Many studies have also revealed that the workability of $\mathrm{AAC}$ is sensitive to the composition and fineness of raw material, alkali concentration and modulus of alkali activator [35, 37-39].

A good understanding of the engineering properties of AAC is certainly important for their successful implementation. This paper provides a state-of-the-art review of research on the mechanical properties of AAC, specifically, on how they compare to the well-documented properties of OPCC. The following mechanical properties are discussed: static mechanical properties such as the compressive strength, tensile strength, elastic modulus, Poisson's ratio, stress-strain relationship, fracture and bonding properties between AAC and steel reinforcement, dynamic mechanical properties, and high-temperature performances. The AACs reviewed are formed from FA, GGBS, or a combination of the two. 


\section{Static Mechanical Properties of Alkali-Activated Concrete}

\subsection{Compressive Strength}

Compressive strength is one of the most static mechanical properties of AAC. It is influenced by several factors such as the type and fineness of the raw cementitous materials, the type and dosage of the alkali activator, the solution to binder ratio, the curing regime, etc. [14, 23-35, 44, 45, 50-52]

\subsubsection{Alkali-Activated Slag Concrete}

Alkali-activated slag concrete (AASC) always shows relatively high early strength and quick strength development. The 1-day compressive strength can achieve $60 \mathrm{MPa}$ and the 1-year compressive strength can exceed $100 \mathrm{MPa}$ [23]. The high mechanical strength of AASC is attributed to two factors: the fast rate of the hydration reactions at elevated $\mathrm{pHs}$, which gives high early age strength; and a dense and homogenous interface transition zone (ITZ), with minimal strength differences between the ITZ and the binders [24].

AASC is sensitive to curing conditions. Bakharev et al. [26] found that heat-cured AASC specimens developed early strength (i.e., 1 day strength) more rapidly than specimens cured at room temperature. However, the later strength of heat-cured specimens was slightly reduced (Fig. 1(a)), which correlated with the inhomogeneity in the microstructure of the matrix. The reason is that the rate of reaction was much faster than that of diffusion. As a result, most of the hydration products remained near the slag grains, leaving interstitial space relatively open, and then more dense precipitates might form a barrier for ion diffusion, leading to an inhomogeneity in the microstructure [26]. Collins and Sanjayan [27] reported that the compressive strength of AASC specimens subjected to bath curing kept developing until 400 days, whereas the sealed AASC specimens gained little strength after 91 days. In contrast, AASC subjected to ambient air exposure curing may exhibit strength retrogression as shown in Fig. 1(b) due to the micro-cracks formed in the matrix. 


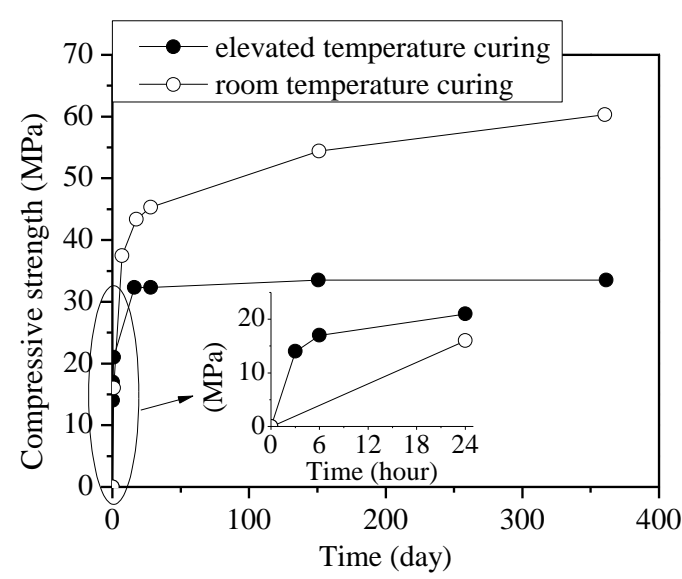

(a) Curing temperature [26]

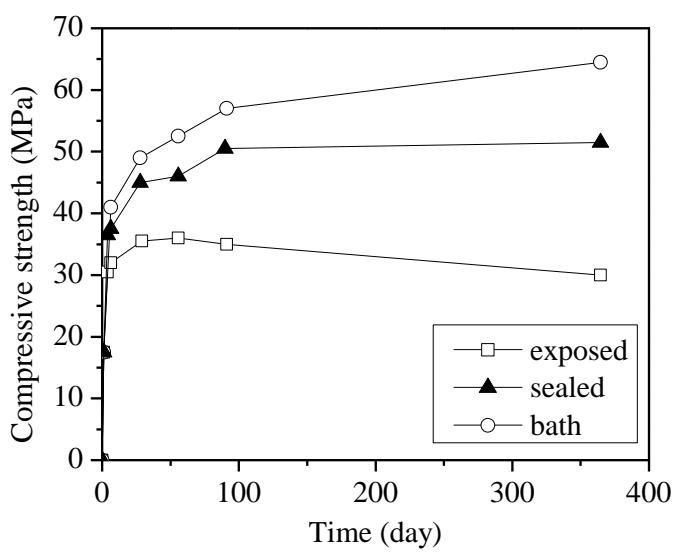

(b) Curing condition [27]

Fig. 1 Effect of curing on the compressive strength of AASC

The effect of an alkaline activator on the compressive strength of AASC has not been systematically studied. Chi [28] found that the compressive strength of AASC increased with the dosage of $\mathrm{Na}_{2} \mathrm{O}$. Comparing the experimental results reported by Collins and Sanjayan [27] and Bakharev [25], it seems that sodium silicate solution led to higher early strength than powered sodium silicate.

\subsubsection{Alkali-Activated Fly Ash Concrete}

AAC based on FA always requires elevated temperature curing to improve its early strength $[14,29]$ because the activation energy is high for FA [30]. As shown in Fig. 2(a), studies have found that the compressive strength of alkali-activated fly ash concrete decreased as the mass ratio of water/solids increased $[31,50]$. The water here also included the water contained in the sodium silicate and sodium hydroxide solutions. The mass of solids was the sum of the fly ash, sodium silicate solids (i.e., the mass of $\mathrm{Na}_{2} \mathrm{O}$ and $\mathrm{SiO}_{2}$ in the sodium silicate solution), and sodium hydroxide flakes. The trends in the test results were similar to the effects of the water/cement ratio on the compressive strength of OPCC, although the chemical processes in these two binders are entirely different. In addition, it is also shown in Fig. 2(a) that the compressive strength of alkali-activated fly ash concrete increased when the curing temperature increased from $30^{\circ} \mathrm{C}$ to $90^{\circ} \mathrm{C}$ [31]. However, the strength gain became less significant when the curing temperature increased from $75^{\circ} \mathrm{C}$ to $90^{\circ} \mathrm{C}$. Joseph and 
Mathew [50] found that the compressive strength of alkali-activated fly ash concrete increased significantly up to $100^{\circ} \mathrm{C}$. Longer curing times generated higher compressive strength, but the improvement became less significant when the curing time exceeded $48 \mathrm{~h}[31,50]$, as shown in Fig. 2(b). A higher molar concentration of sodium hydroxide solution resulted in higher compressive strength [31] because the higher $\mathrm{pH}$ caused an increasing breakage of the glassy chain at the surface of the fly ash and promoted the reaction of the internal $\mathrm{Si}$ and $\mathrm{Al}$ to form gel phases, which provide structural strength. Joseph and Mathew [50] found the ideal concentration of sodium hydroxide solution, as shown in Fig. 2(c). At concentrations higher than this ideal, the compressive strength was reduced, as the excess $\mathrm{OH}^{-}$in the matrix hinders the condensation of silicate species [51, 52]. The mass ratio of sodium silicate solution to sodium hydroxide solution also had a significant influence on the compressive strength of alkali-activated fly ash concrete $[31,45,50]$. It can be seen from Fig. 2(d) that the compressive strength of alkali-activated fly ash concrete increased with the mass ratio of sodium silicate solution to sodium hydroxide solution until the ration reached 2.5, and then it decreased. Hardjito [31] obtained similar results; in that study, the compressive strength of alkali-activated fly ash concrete increased when the mass ratio of sodium silicate solution to sodium hydroxide solution increased from 0.4 to 2.5 , regardless of the alkaline concentration.

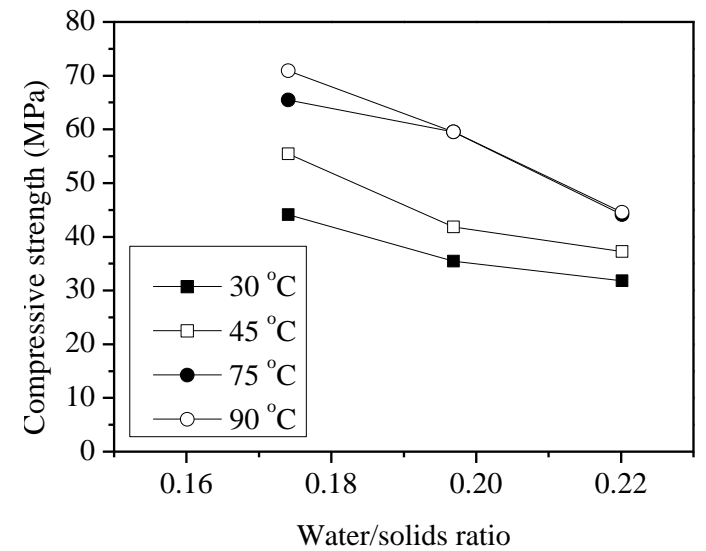

(a) Curing temperature and water/solids ratio [31]

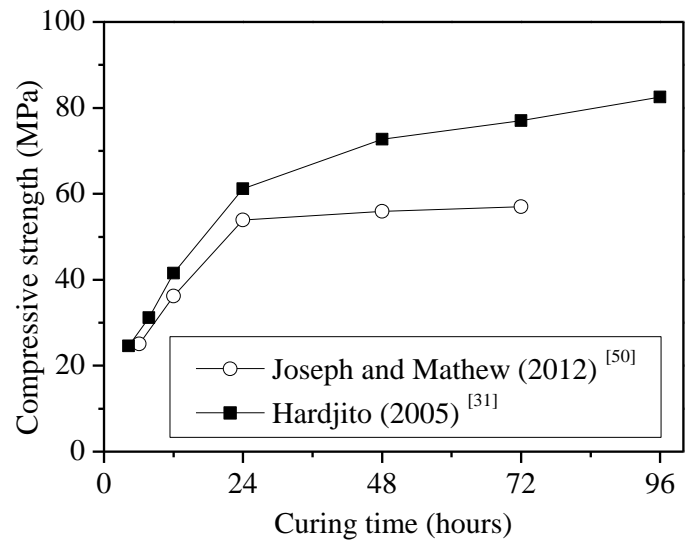

(b) Curing time [31][50] 


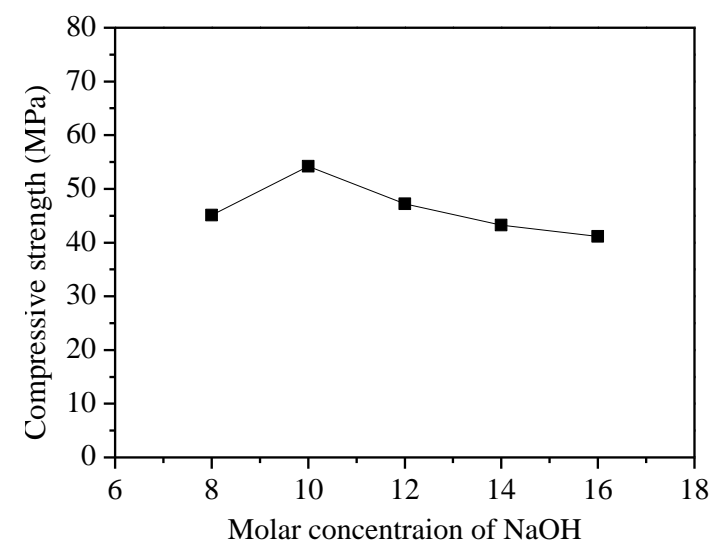

(c) Molar concentration of $\mathrm{NaOH}[50]$

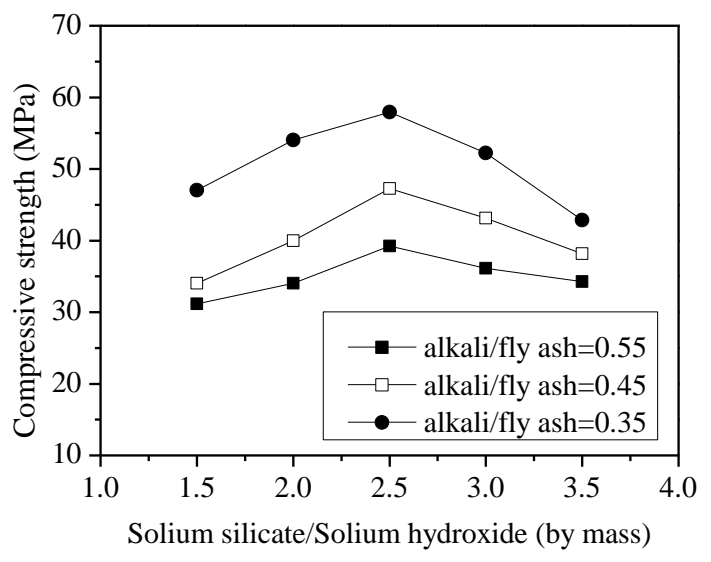

(d) Mass ratio of sodium silicate solution to sodium hydroxide solution [50]

Fig. 2 Parametric effects on the compressive strength of alkali-activated fly ash concrete

\subsubsection{Alkali-Activated Slag-Fly Ash Concrete}

To avoid heat curing and improve the early age strength, recent studies have examined the combination of high-calcium with low-calcium or calcium-free raw materials to generate AAC. These studies showed that the compressive strength of the alkali-activated slag-fly ash concrete increased with the amount of slag [34, 35, 44]. The experimental results obtained by Lee and Lee [44], depicted in Fig. 3(a), show that the 28-day compressive strength increased from $15.5 \mathrm{MPa}$ to $23.0 \mathrm{MPa}$ as the replacement ratio of slag for fly ash increased from $10 \%$ to $15 \%$. This increase in strength with the addition of slag into the matrix is attributed to the formation of $\mathrm{C}-\mathrm{S}-\mathrm{H}$ gel phases and the condensation of the microstructure. In addition, the water/solid ratio had a significant influence on the compressive strength of alkali-activated slag-fly ash concrete [35]. It can be seen from Fig. 3(b) that increasing the water/solid ratio from 0.18 to 0.22 significantly reduced the strength of the concrete. Furthermore, Nath and Sarker [35] found that the variation in the sodium silicate to sodium hydroxide ratio from 1.5 to 2.5 had a slight influence on the compressive strength of alkali-activated slag-fly ash concrete. The compressive strength of the alkali-activated slag-fly ash concrete developed gradually when cured at ambient temperature. However, the concrete samples cured at elevated temperatures achieved higher early strength but negligible strength gain over time [35]. 


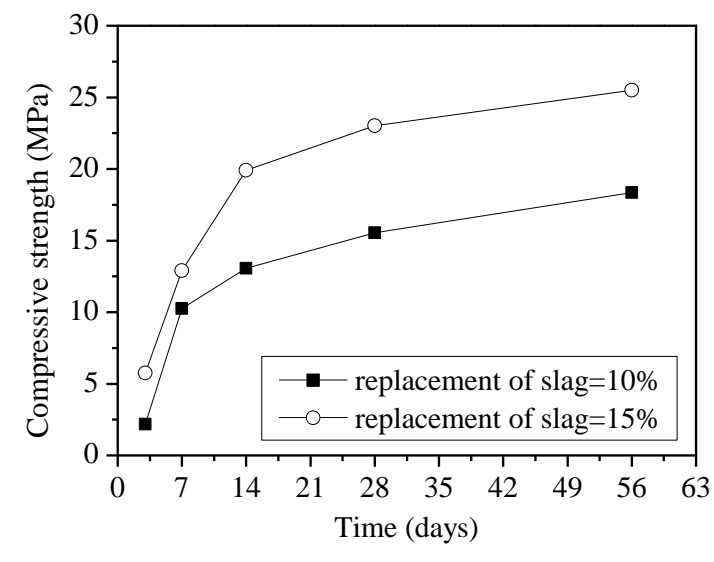

(a) Replacement ratio of slag [44]

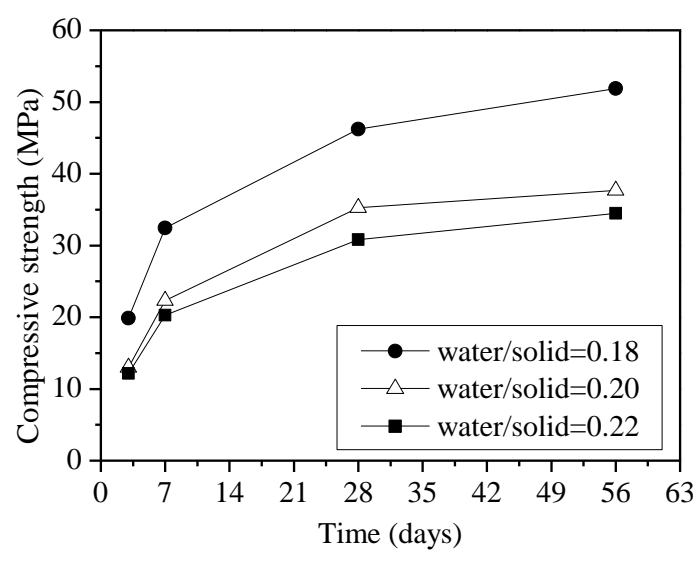

(b) Water/solid ratio [35]

Fig. 3 Parametric effects on the compressive strength of alkali-activated slag-fly ash concrete

\subsection{Elastic Modulus}

The elastic modulus of concrete is an important parameter in concrete design and analysis; it mainly depends on the type and content of the coarse aggregate and the elastic modulus of the paste. The modulus of elasticity of OPCC can be predicted using the empirical formulae suggested by codes of practice that are in turn based on numerous experimental results. For example, the elastic modulus of normal weight OPCC can be estimated by the CEB-FIP [48] model code as follows:

$$
E_{c}=0.85 \times 2.15 \times 10^{4}\left(f_{c} / 10\right)^{1 / 3}
$$

where $E_{c}$ is the modulus of elasticity of OPCC at 28 days (MPa) and $f_{c}$ is the average compressive strength of OPCC at 28 days (MPa). According to the ACI building code 318 [47], the elastic modulus of light weight OPCC (unit weight between 1500 and $2500 \mathrm{~kg} / \mathrm{m}^{3}$ ) can be determined by using Eq. (2). In the case of normal weight OPCC, this equation can be simplified to Eq. (3).

$$
\begin{gathered}
E_{c}=0.043 w_{c}^{1.5}\left(f_{c}^{\prime}\right)^{1 / 2} \\
E_{c}=4700\left(f_{c}^{\prime}\right)^{1 / 2}
\end{gathered}
$$

where $w_{c}$ is the unit weight $\left(\mathrm{kg} / \mathrm{m}^{3}\right)$. 
Several authors have reported the modulus of elasticity of various types of AAC, but their conclusions are inconsistent [37, 41, 43-45, 50, 56, 57]. Most of these existing studies reported that the elastic modulus of AAC is in the range of 10-40GPa, which is similar to that of OPCC.

\subsubsection{Alkali-Activated Slag Concrete}

Collins and Sanjayan [37] found that the elastic modulus of AASC with the use of different alkali activators was marginally lower than that of OPCC. Douglas et al. [40] stated that the elastic modulus of AASC can be estimated from the corresponding compressive strength as described in the ACI building code 318 (see Fig. 4(a)). Similarly, Yang et al. [56] stated that the elastic modulus of AASC activated by calcium hydroxide can be approximately predicted by the ACI building code 318 (see Fig. 4(a)); they also proposed a refined prediction formula as shown in Eq. (4). In contrast, Thomas and Peethamparan [43] reported that the modulus of elasticity of AASC varied marginally with the compressive strength and that the ACI building code 318 (Eq. (3)) fit poorly with their experimental results (see Fig. 4(a)), perhaps because initial micro-cracks in the matrix may decrease the elastic modulus of the concrete. Such flaws are aggravated by increases in compressive strength [27], which may further adversely affect the elastic modulus of AASC.

$$
E_{c}=4600\left(w_{c} / 2200\right)^{1.5}\left(f_{c}^{\prime}\right)^{1 / 2}
$$

\subsubsection{Alkali-Activated Fly Ash Concrete}

The elastic modulus of alkali-activated fly ash concrete reported by Fernández-Jiménez et al. [45] was in the range of 10-20 GPa (see Fig. 4(b)), whereas the corresponding OPCC had a higher elastic modulus in the range of 25-35 GPa. However, Joseph and Mathew [50] found that the modulus of elasticity of alkali-activated fly ash concretes was in the range of 40-60 GPa (see Fig. 4(b)), which was much higher than that of their OPCC counterparts with similar compressive 
strength. The raw cementitious materials used in the above two studies were all low calcium fly ash (ASTM, Class F). The curing temperature $\left(100^{\circ} \mathrm{C}\right)$ was higher and curing time $(24 \mathrm{~h})$ was longer in the latter study than in the former one $\left(80^{\circ} \mathrm{C}\right.$ and $20 \mathrm{~h}$, respectively), leading to higher crystallinity and thus higher elastic modulus. The use of a higher content of coarse aggregate (i.e., $1204 \mathrm{~kg} / \mathrm{m}^{3}$ ) in Joseph and Mathew's study compared to the study of Fernández-Jiménez et al. (i.e., $1037 \mathrm{~kg} / \mathrm{m}^{3}$ ) may be another reason for the different results.

Thomas and Peethamparan [43] proposed two fitting models in the same paper to predict the modulus of elasticity of alkali-activated fly ash concrete; here they are given by Eq. (5) and Eq. (6), whose coefficients of determination are 0.58 and 0.60 , respectively. The ACI building code 318 fits their outcomes reasonably well $\left(R^{2}=0.54\right)$ (see Fig. 4(b)).

$$
\begin{aligned}
& E_{c}=2900\left(f_{c}^{\prime}\right)^{3 / 5} \\
& E_{c}=4400\left(f_{c}^{\prime}\right)^{1 / 2}
\end{aligned}
$$

It can be seen from Fig. 4(b) that the elastic modulus of alkali-activated fly ash concrete obtained by Thomas and Peethamparan [43] were much higher than those gained by Fernández-Jiménez et al. [45]. The different results may be attributed to the different cementitious raw materials used. The fly ash used by Fernández-Jiménez et al. was low calcium fly ash (ASTM Class F, the mass ratio of $\mathrm{CaO}$ was 2.44\%), whereas high calcium fly ash (ASTM Class $\mathrm{C}$, the mass ratio of $\mathrm{CaO}$ was $23.4 \%$ ) was used in Thomas and Peethamparan's study. The main hydration products of alkali-activated Class F fly ash is N-A-S-H gel, whereas C-S-H gel and N-A-S-H gel co-exist in alkali-activated Class $\mathrm{C}$ fly ash matrix [53]. Hence, there were more C-S-H gels generated in the binder used by Fernández-Jiménez et al. Puertas et al. [54] demonstrated that the Young's modulus of C-S-H gel in the sodium hydroxide-activated slag was in the range of $12-43 \mathrm{GPa}$, whereas this value was $28-47$ 
GPa when sodium silicate was used as the alkaline activator. However, the intrinsic Young's modulus of N-A-S-H gels formed in the low calcium fly ash was around 17-18 GPa [55], which was much lower than that of C-S-H gel. Therefore, the elastic modulus of the alkali-activated Class $\mathrm{C}$ fly ash concrete should be higher than that of the alkali-activated Class F fly ash concrete.

\subsubsection{Alkali-Activated Slag-Fly Ash Concrete}

Sofi et al. [41] reported that the elastic modulus of the alkali-activated slag-fly ash concrete (see Fig. 4(c)) fell within the upper and lower bounds suggested by the AS 3600 [46] model, although it was underestimated by the ACI building code 318 . Lee and Lee [44] stated that the elastic modulus of most alkali-activated slag-fly ash concrete specimens were $20-40 \%$ lower than the predictions of the ACI building code 318; they proposed a relationship between the elastic modulus and compressive strength as described in Eq. (7) (see Fig. 4(c)). Although the raw cementitious materials used in Sofi's and Lee and Lee's study were similar and the curing conditions were all at room temperature, the elastic modulus of the alkali-activated slag-fly ash concrete in the former case was much higher than in the latter case. The mass ratio of slag/fly ash in Sofi's study was 2.2 , whereas this value was less than 0.43 in Lee and Lee's study. As C-S-H gel is the main hydration product of the alkali-activated slag, much more C-S-H gel was formed in Sofi's matrix. As previously mentioned, the Young's modulus of C-S-H gel generated in the alkali-activated slag is much higher than that of the N-A-S-H gel formed in the alkali-activated fly ash $[54,55]$. Hence, the elastic modulus of the alkali-activated slag-fly ash concrete with higher slag/fly ash mass ratios should be higher than that of the concrete with lower slag/fly ash mass ratios.

$$
E_{c}=5300\left(f_{c}\right)^{1 / 3}
$$






(a) Alkali-activated slag concrete

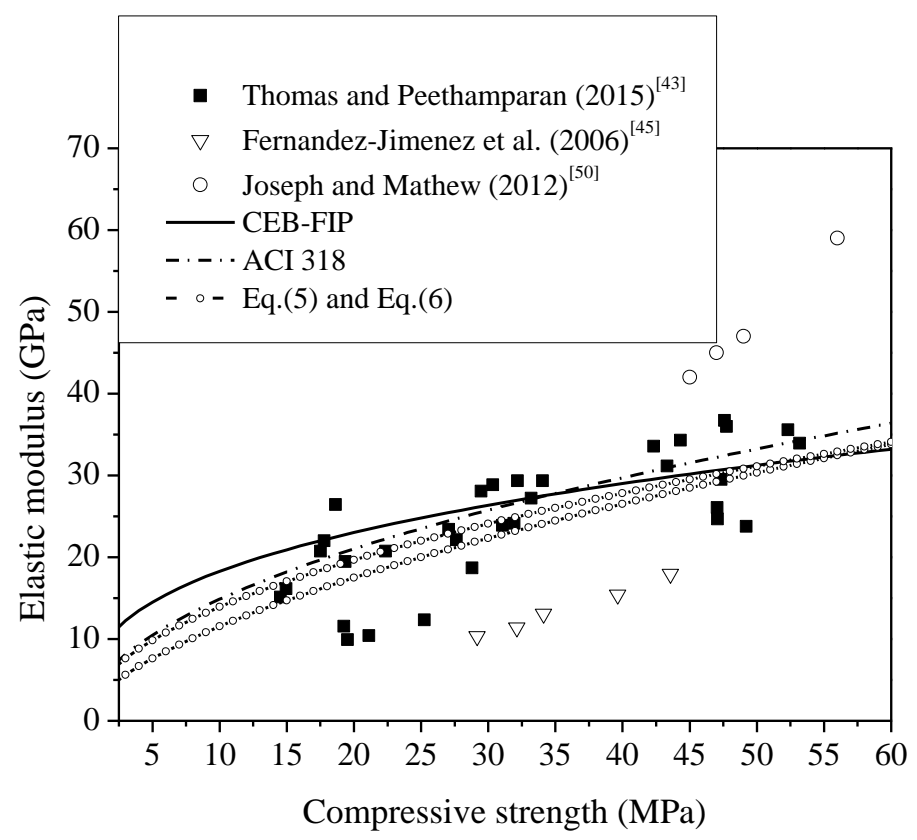

(b) Alkali-activated fly ash concrete 


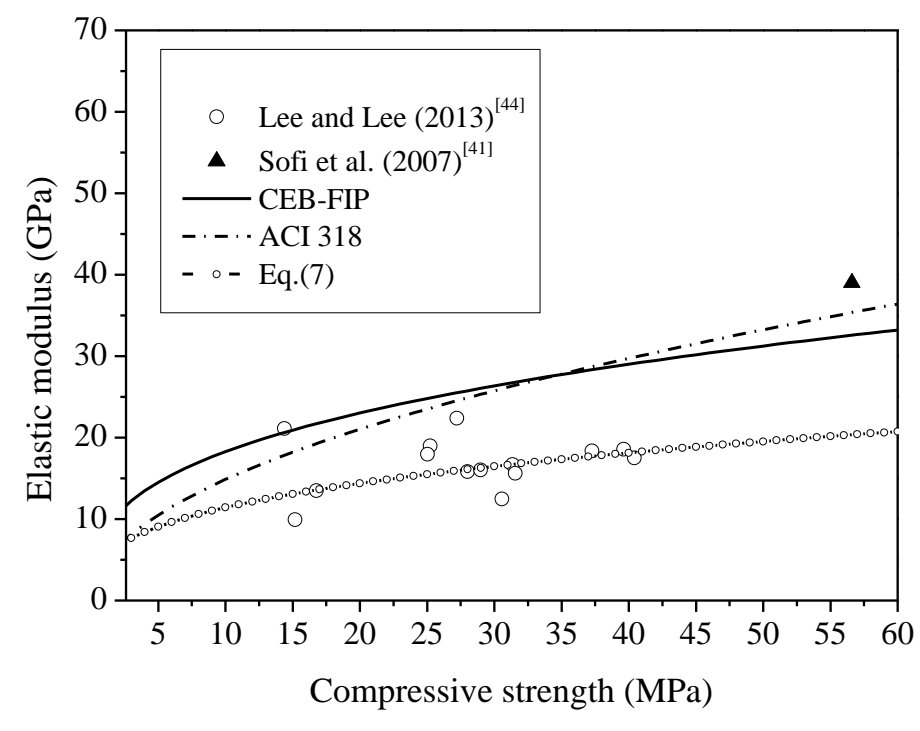

(c) Alkali-activated slag-fly ash concrete

Fig. 4 Relationship between the elastic modulus and compressive strength

Together, the experimental results illustrated in Fig. 5 show that there is significant discrepancies in the test data. The models recommended by codes of practice for OPCC do not precisely predict the test database (ACI building code 318 with $R^{2}=0.302$; CEB-FIP model with $\left.R^{2}=0.300\right)$. It is known that the elastic modulus of OPCC mainly depends on the type and content of the coarse aggregate. However, the microstructure, composition, and degree of hydration also have significant effects on the elastic modulus of AAC. The Si/Al ratio of the initial composition also has an influence on the elastic modulus of alkali-activated binders [42, 58]. Further research is necessary to establish a quantitative relationship between the elastic modulus and compressive strength of AAC. 


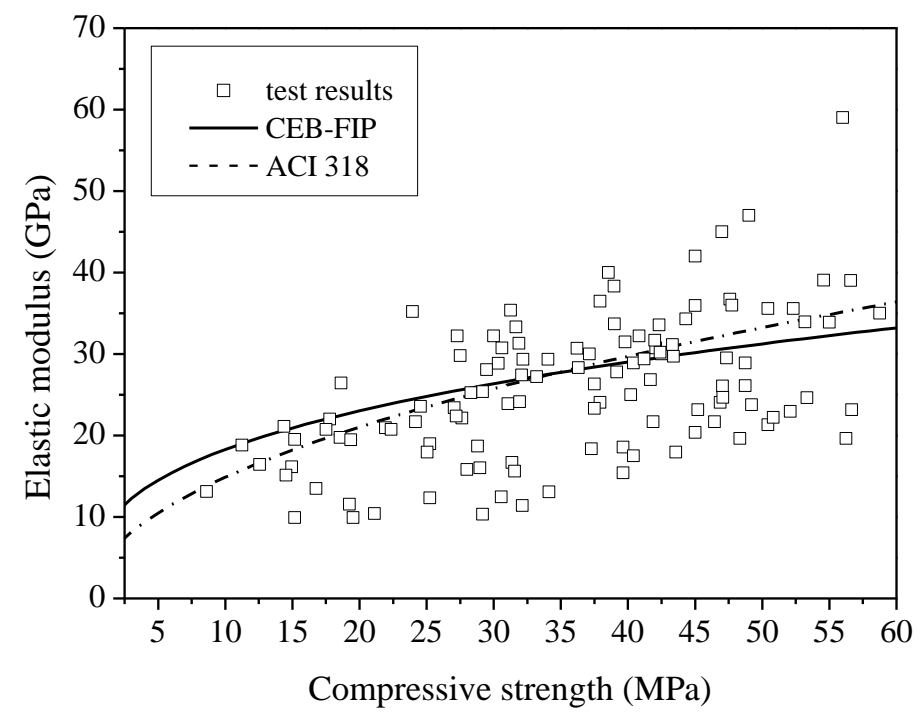

Fig. 5 Summary of the relationship between the elastic modulus and compressive strength

\subsection{Compressive Stress-Strain Relationship}

The compressive stress-strain relationship of concrete is the most fundamental constitutive law used in the nonlinear analysis of concrete structures. The stress-strain relationships of OPCC under uniaxial compression can be predicted using the empirical formulae suggested by codes of practice. Here, only the CEB-FIP model is illustrated in Fig. 6 for the purpose of comparing OPCC with AAC.

$$
\begin{gathered}
\sigma_{c}=-\frac{\frac{E_{c i} \varepsilon_{c}}{E_{c 1} \varepsilon_{c 1}}-\left(\frac{\varepsilon_{c}}{\varepsilon_{c 1}}\right)^{2}}{1+\left(\frac{E_{c i}}{E_{c 1}}-2\right) \frac{\varepsilon_{c}}{\varepsilon_{c 1}}} f_{c m}, \text { for }\left|\varepsilon_{c}\right|<\left|\varepsilon_{c, \lim }\right| \\
\sigma_{c}=-\left[\left(\frac{1}{\varepsilon_{c, \lim } / \varepsilon_{c 1}} \xi-\frac{2}{\left(\varepsilon_{c, \lim / \varepsilon_{c 1}}\right)^{2}}\right]\left(\frac{\varepsilon_{c}}{\varepsilon_{c 1}}\right)^{2}+\left(\frac{4}{\varepsilon_{c, \lim / \varepsilon_{c 1}}}-\xi\right) \frac{\varepsilon_{c}}{\varepsilon_{c 1}}\right]^{-1} f_{c m} \text {, for }\left|\varepsilon_{c}\right|>\left|\varepsilon_{c, \lim }\right|
\end{gathered}
$$

with 


$$
\begin{gathered}
\xi=\frac{4\left[\left(\frac{\varepsilon_{c, \lim }}{\varepsilon_{c 1}}\right)^{2}\left(\frac{E_{c i}}{E_{c 1}}-2\right)+2 \frac{\varepsilon_{c, \lim }}{\varepsilon_{c 1}}-\frac{E_{c i}}{E_{c 1}}\right]}{\left[\frac{\varepsilon_{c, \lim }}{\varepsilon_{c 1}}\left(\frac{E_{c i}}{E_{c 1}}-2\right)+1\right]^{2}} \\
\frac{\varepsilon_{c, \lim }}{\varepsilon_{c 1}}=\frac{1}{2}\left(\frac{1}{2} \frac{E_{c i}}{E_{c 1}}+1\right)+\left(\frac{1}{4}\left(\frac{1}{2} \frac{E_{c i}}{E_{c 1}}+1\right)^{2}-\frac{1}{2}\right)^{1 / 2} \\
E_{c i}=E_{c o}\left(f_{c m} / f_{c m 0}\right)^{1 / 3} \\
E_{c 1}=f_{c m} / 0.0022 \mathrm{MPa}
\end{gathered}
$$

where $\varepsilon_{c 1}=-0.0022 \mu \varepsilon, f_{c m 0}=10 \mathrm{MPa}, \quad E_{c o}=2.1 \times 10^{4} \mathrm{MPa} \quad, \quad \varepsilon_{c}$ is the compression strain, $\sigma_{c}$ is the compression stress, and $E_{c 1}$ is the secant modulus from the origin to the peak compressive strength.

\subsubsection{Alkali-Activated Slag Concrete}

Few studies have reported the stress-strain relationship of AASC under uniaxial compressive load. Yang et al. [56] and Thomas and Peethamparan [43] studied the stress-strain relationship of AASC and their results are shown in Fig. 6(a). The characteristic of the stress-strain curve of AASC was significantly influenced by its compressive strength. The initial stiffness and the strain at the peak stress increased with the compressive strength, as commonly observed for OPCC [61]. Yang et al. [56] concluded that, in general, the CEB-FIP model does not match the characteristics of the stress-strain curves of AASC. The model overestimated the ascending branch and predicted a steeper descending branch, which implied that AASC was more ductile than OPCC given a similar compressive strength (Fig. 6(a)). Thomas and Peethamparan [43] confirmed the same trend for the ascending branch, but observed a more rapid drop in the descending branch (i.e., more brittle behavior), which was the opposite of the observations reported by Yang et al. They attributed the increased brittleness, which had also been observed in other studies [62], to the high prevalence of micro-cracks in AASC [27]. 


\subsubsection{Alkali-Activated Fly Ash Concrete}

Reports on the stress-strain relationship of the alkali-activated fly ash concrete under uniaxial compression are also very limited. Hardjito [31] studied the stress-strain relationship of alkali-activated fly ash concrete under an uniaxial compressive load and demonstrated that the measured stress-strain relationship can be predicted using the model that Collins et al. [63] developed for high strength concrete. His experimental results are shown in Fig. 6(b). Compared to the CEB-FIP model prediction, a higher initial stiffness but a relatively brittle descending branch was observed for the test specimens with higher compressive strength. The stress-strain curve of the sample with lower compressive strength fit reasonably well with the CEB-FIP model prediction. Thomas and Peethamparan [43] experimentally obtained the stress-strain curves of the alkali-activated fly ash concrete at two different compressive strengths. The sample with a lower compressive strength met the CEB-FIP model prediction reasonably well; however, the sample with the higher compressive strength deviated significantly from the CEB-FIP model prediction.

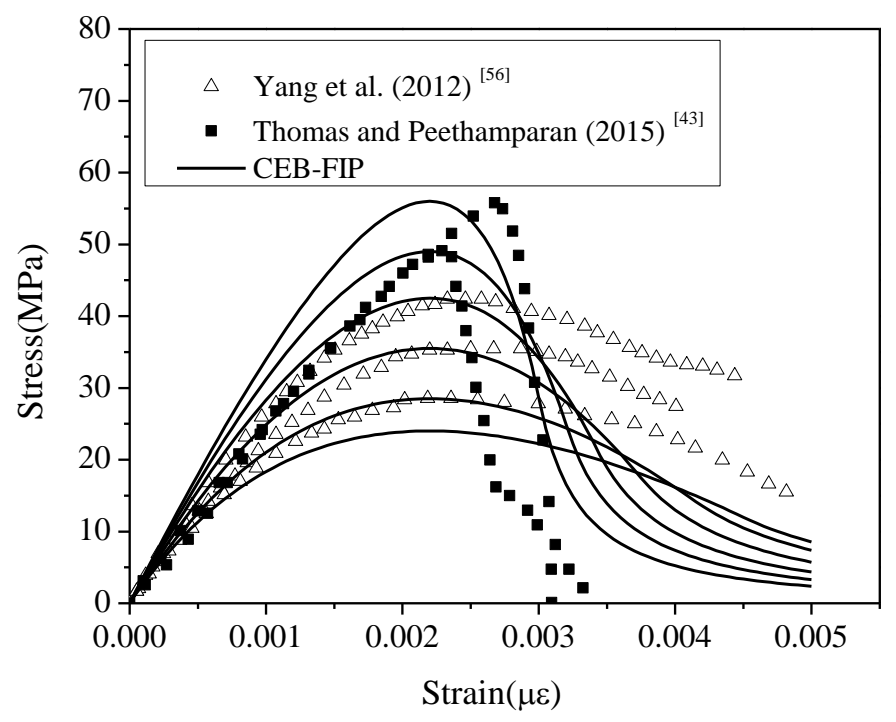

(a) Alkali-activated slag concrete 


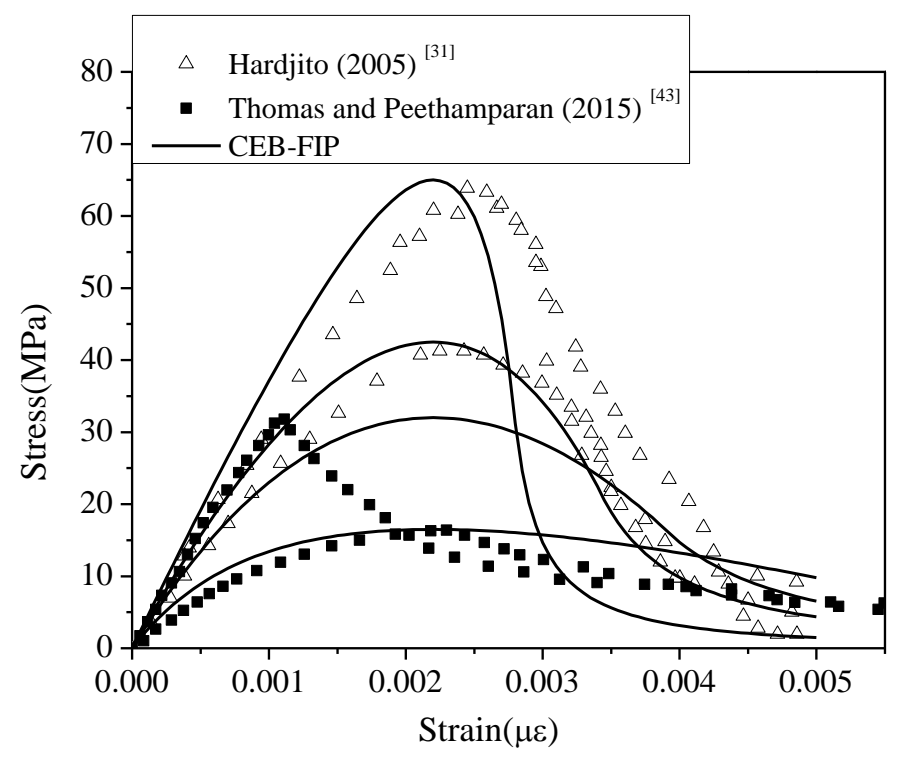

(b) Alkali-activated fly ash concrete

Fig. 6 Stress-strain relationship of alkali-activated concrete subjected to uniaxial compression

Until now, due to limited experimental results, no attempts have been made to develop a generic model for predicting the stress-strain relationship of AAC. It seems that the ascending and descending branches of the stress-strain curves subjected to uniaxial compression are different from those of OPCC. More experimental results are necessary to ascertain quantitatively the stress-strain relationship of AAC under uniaxial compression.

\subsection{Poisson's Ratio}

Although several studies have reported the Poisson's ratio of AAC, the results have been inconsistent. Sofi et al. [41] observed that the values of the Poisson's ratio for all of the alkali-activated slag-fly ash concrete specimens fell between 0.23 and 0.26 , which were slightly higher than those of normal strength OPCC (0.11-0.21) [59]. Similarly, Bondar et al. [60] reported that the Poisson's ratio of alkali-activated natural pozzolans concrete was $19.2 \%$ larger than that of OPCC. However, Thomas and Peethamparan [43] reported that the Poisson's ratio for alkali-activated fly ash concrete and alkali-activated slag concrete was 0.127 \pm 0.003; Diaz and Allouche [57] found that the Poisson's ratio of alkali-activated fly ash concrete was in the range of 0.08-0.17 with an average value of 0.13 ; Hardjito [31] found that the Poisson's ratio 
of alkali-activated fly ash concrete was in the range of $0.12-0.16$. These were all lower than the average value for the Poisson's ratio of OPCC (i.e., $\approx 0.18$ ).

\subsection{Tensile Strength}

The tensile strength of concrete is only a fraction of its compressive strength and the tension failure of concrete is very brittle. The tensile strength $f_{c t}$ of OPCC has been widely studied and can be conveniently measured by conducting the splitting tensile strength test or estimated by the compressive strength $f_{c}^{\prime}$.

The ACI building code 318 suggests that the tensile strength of concrete can be estimated from the compressive strength using Eq. (14).

$$
f_{c t}=0.56 \sqrt{f_{c}^{\prime}}
$$

where $f_{c t}$ is the splitting tensile strength $(\mathrm{MPa})$ and $f_{c}^{\prime}$ is the compressive strength (MPa).

In contrast, the relationship between the mean tensile strength $f_{c t m}$ and the characteristic compressive cylinder strength $f_{c k}$ at 28 days suggested by Eurocode 2 [49] are as follows:

$$
\begin{gathered}
\left\{\begin{array}{cc}
f_{c t m}=0.3\left(f_{c k}\right)^{2 / 3}, & f_{c k} \leq 50 \mathrm{MPa} \\
f_{c t m}=2.12 \times \ln \left(1+\left(f_{c m} / 10\right)\right), & f_{c k}>50 \mathrm{MPa}
\end{array}\right. \\
f_{c m}=f_{c k}+8 \\
f_{c t m}=0.9 f_{c t, s p}
\end{gathered}
$$

where $f_{c m}$ is the mean compressive strength, $f_{c t m}$ is the mean tensile strength (MPa), and $f_{c t, s p}$ is the splitting tensile strength (MPa). 


\subsubsection{Alkali-Activated Slag Concrete}

Yang et al. [56] studied the splitting tensile strength of AASC with calcium hydroxide as an activator and different water/binder ratios and reported that the splitting tensile strengths of AASC were higher than those predicted by the Eurocode 2, but agreed well with the ACI building code 318 (see Fig. 7(a)). Similarly, Chi [28] studied the splitting tensile strength of AASC using combined activators of sodium silicate and sodium hydroxide (see Fig. 7(a)) and found that the splitting tensile strength obtained by Chi [28] also fit reasonably well with the ACI building code 318 predictions.

\subsubsection{Alkali-Activated Fly Ash Concrete}

Ryu et al. [36] obtained some experimental results for the splitting tensile strength of alkali-activated fly ash concrete (see Fig. 7(b)) that fit reasonably well with the estimation of Eurocode 2. However, the splitting tensile strengths of alkali-activated fly ash concrete obtained by Sarker [65] (see Fig. 7(b)) were slightly higher than those obtained by Ryu et al. [36]. The curing conditions in these two studies were the same $\left(60^{\circ} \mathrm{C}, 24 \mathrm{~h}\right)$ and the raw materials used were all Class $\mathrm{F}$ fly ash. The differences in the splitting tensile strength should be attributed to the different water/fly ash ratio and alkali concentration adopted in these two studies. The water/fly ash ratio in Sarker's study was 0.56 , whereas Ryu et al. used a ratio of less than 0.30 . The smaller water/fly ash ratio lead to a less porous matrix, which made it denser and more homogenous and resulted in a higher splitting tensile strength. In addition, Sarker used a sodium hydroxide solution of $9 \mathrm{M}$, whereas Ryu et al. used a concentration of alkali solution of $14 \mathrm{M}$. The higher alkali concentration could have improved the geopolymerization of the fly ash.

\subsubsection{Alkali-Activated Slag-Fly Ash Concrete}

Sofi et al. [41] found that most of the measured splitting tensile strengths of alkali-activated slag-fly ash concrete were lower than those predicted by the ACI building code 318. According to their experimental results (see Fig. 7(c)), the splitting 
tensile strength of alkali-activated slag-fly ash concrete can be estimated by Eq. (18). Similarly, Lee and Lee [44] found that the splitting tensile strength of alkali-activated slag-fly ash concrete had a linear relationship with the square root of the compressive strength; the constant of proportionality was 0.45 (Eq. (19)), which was slightly lower than the fitting outcomes obtained by Sofi et al. [41].

$$
\begin{gathered}
f_{c t}=0.48 \sqrt{f_{c}^{\prime}} \\
f_{c t}=0.45 \sqrt{f_{c}^{\prime}}
\end{gathered}
$$

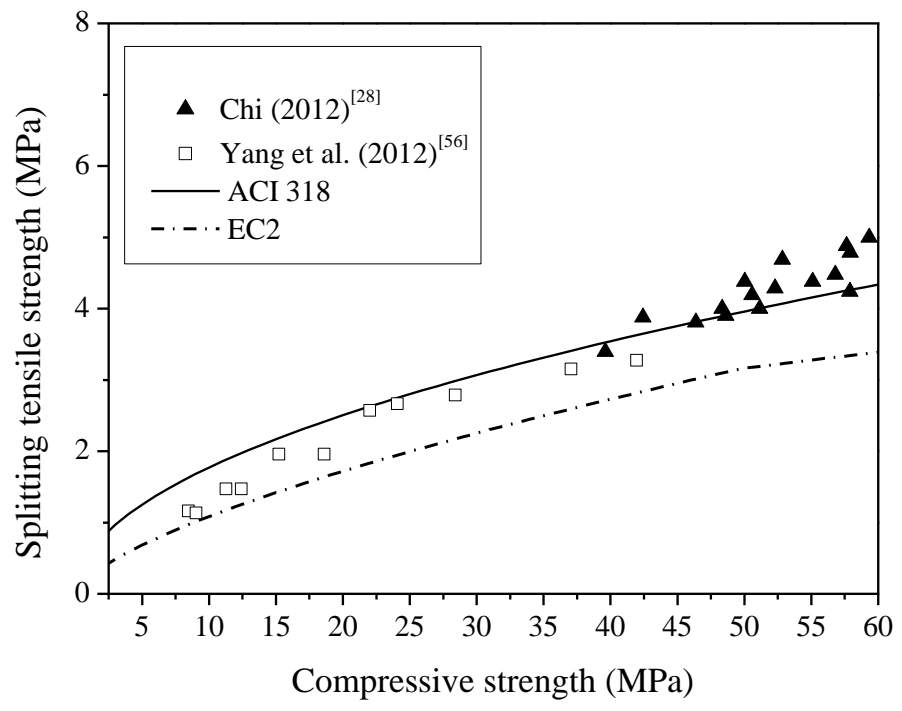

(a) Alkali-activated slag concrete



(b) Alkali-activated fly ash concrete 


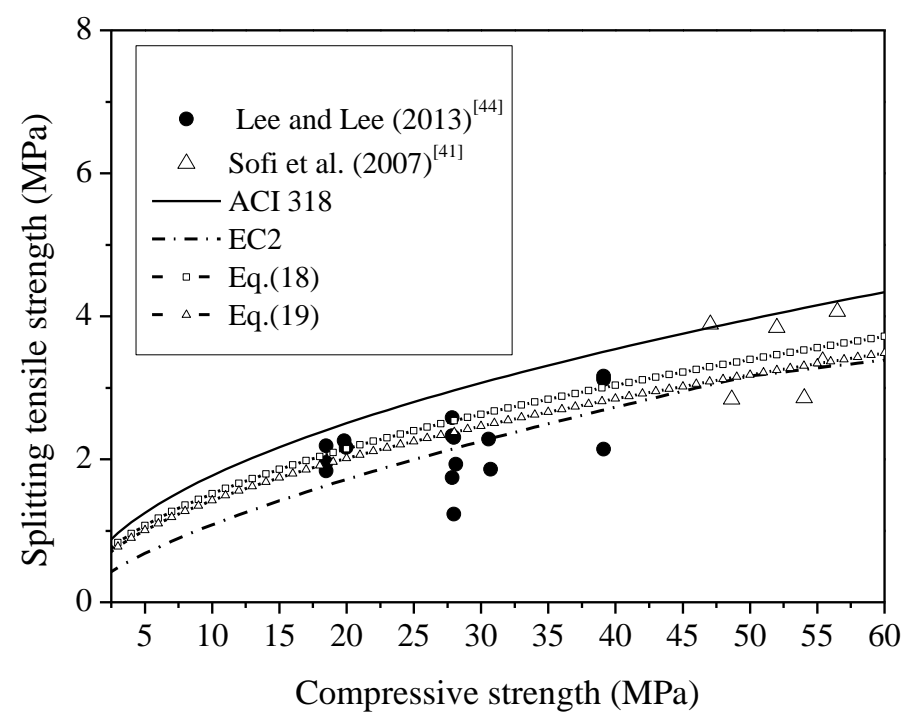

(c) Alkali-activated slag-fly ash concrete

Fig. 7 Relationship between the splitting tensile strength and compressive strength

Although previous studies have reached conflicting conclusions, most of the experimental results have found that the splitting tensile strength of AAC is close to the predictions of the ACI building code 318 or Eurocode 2. Drawing on these results in Fig. 8, this paper identifies two equations similar to those in the ACI building code 318 (Eq. (20) with $R^{2}=0.797$ ) and Eurocode 2 (Eq. (21) with $R^{2}=0.809$ ). Given the limited experimental results, the validity of the proposed equations needs further verification.

$$
\begin{gathered}
f_{c t}=0.527 \sqrt{f_{c}^{\prime}} \\
f_{c t}=0.163\left(f_{c}^{\prime}\right)^{0.818}
\end{gathered}
$$




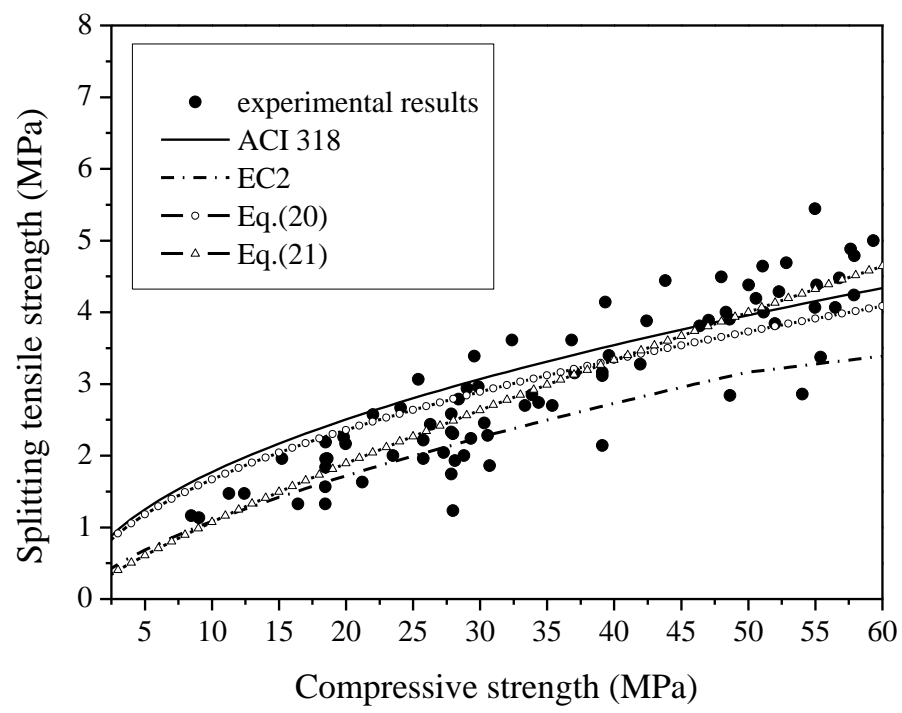

Fig. 8 Summary of the relationship between splitting tensile strength and compressive strength

\subsection{Fracture Properties}

The fracture characteristics of a material are used to describe the formation and propagation of its cracks, and reflect the brittleness and response of the material under tension. The crack path in concrete mainly depends on the strength of the ITZ between the aggregates and the binder matrix, and the strengths of the binder and the aggregates themselves. Numerous studies have been conducted on the fracture properties of OPCC; the frequently studied fracture parameters include the fracture energy $G_{\mathrm{F}}$, the characteristic length $l_{\mathrm{ch}}$, and the fracture toughness (i.e., the initial fracture toughness $K_{\text {ini }}$ and critical fracture toughness $K_{\text {un }}$ ). However, there are very limited studies on the fracture properties of AAC.

Pan et al. [72] studied the fracture properties of alkali-activated fly ash concrete cured at $60^{\circ} \mathrm{C}$ for different curing times using three-point bending (TPB) tests of notched beam specimens, conducted according to the recommendation of RILEM TC50-FMC [75]. Fig. 9 shows that the descending branch of the load-deflection curve of alkali-activated fly ash concrete was steeper than that of OPCC given a similar compressive strength. The characteristic length $l_{\mathrm{ch}}$ of OPCC was almost three times higher and the fracture energy was about $24 \%$ more than that of the alkali-activated fly ash concrete. All of these conclusions indicated that the alkali-activated fly ash 
concrete exhibited a higher brittleness than its OPCC counterpart given a similar compressive strength.

Sarker et al. [73] also studied the fracture behavior of heat-cured alkali-activated fly ash concrete using TPB tests of notched beam specimens. As shown in Fig. 9. the peak load of alkali-activated fly ash concrete specimens was generally higher, and the descending part of the load-deflection curve was steeper than those of the OPCC specimens of similar compressive strength. The failure modes of the alkali-activated fly ash concrete specimens were found to be more brittle and the fracture planes were smoother than the OPCC specimens. All of these phenomena illustrate that the alkali-activated fly ash concrete exhibited higher brittleness than its OPCC counterpart.

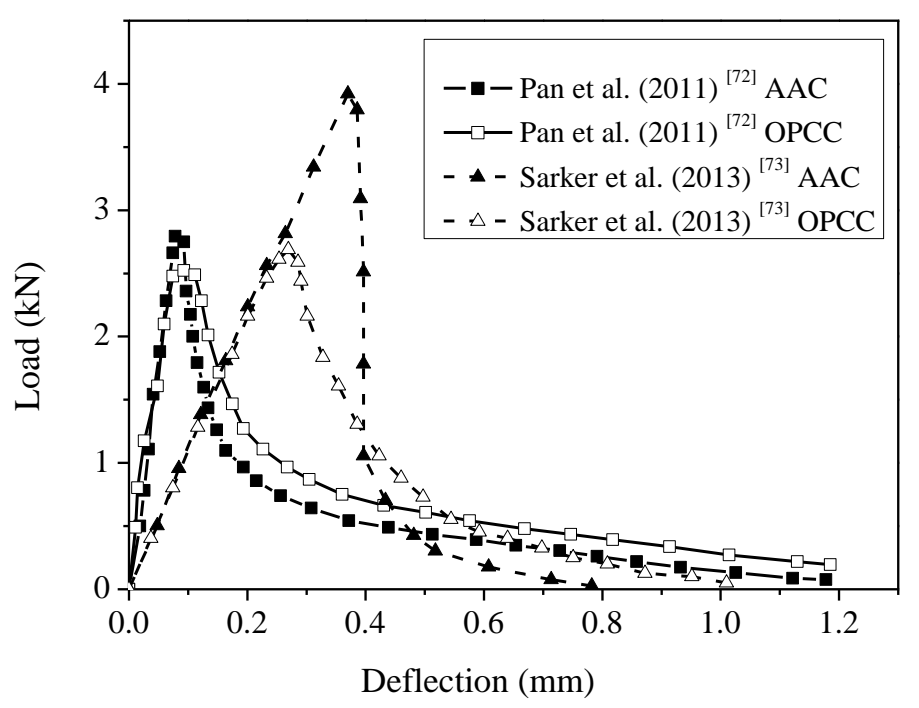

Fig. 9 Load-deflection curves of alkali-activated and OPC concrete subjected to three-point bending

The fracture energy of OPCC, specifically, its compressive strength and maximum aggregate size, can be estimated by the CEB-FIP model using Eq. (22). After considering the influence of the water to cement ratio and the shape of the aggregate on the fracture energy, Bazant and Becq-Giraduon [74] proposed Eq. (23) based on their statistical analysis of 238 test data with a wide range of specimen sizes. 


$$
\begin{aligned}
G_{F} & =\left(0.0469 \times D_{\text {max }}^{2}-0.5 D_{\text {max }}+26\right) \times\left(f_{c} / 10\right)^{0.7} \\
G_{F} & =2.5 \alpha_{0}\left(\frac{f_{c}}{0.051}\right)^{0.46}\left(1+\frac{D_{\max }}{11.27}\right)^{0.22}\left(\frac{w}{c}\right)^{-0.30}
\end{aligned}
$$

where $D_{\max }$ is the maximum aggregate size $(\mathrm{mm}), f_{c}$ is the compressive strength (MPa), $\alpha_{0}$ is the aggregate shape factor $\left(\alpha_{0}=1\right.$ for rounded aggregates, $\alpha_{0}=1.44$ for angular aggregetes), and $w / c$ is the water to cement ratio of concrete.

In Fig. 10, the fracture energies of the alkali-activated fly ash concrete specimens obtained by Pan et al. [72] and Sarker et al. [73] are compared to the predictions of the CEB-FIP model and the Bazant and Becq-Giraduon model. Here, the liquid to fly ash ratio in the alkali-activated fly ash concrete is used as an equivalent term of the water to cement ratio of OPCC. The fracture energy of concrete is generally believed to be governed by the size and angularity of the coarse aggregates, the microstructure of the paste, and the ITZ between the aggregates and the paste. The coarse aggregates used for the alkali-activated fly ash concrete and OPCC are usually the same. Therefore, the characteristics of the paste and ITZ seem to be the predominant sources of the differences in the fracture energies between the alkali-activated fly ash concrete and the OPCC. Pan et al. [72] found that the fracture energy of alkali-activated fly ash concrete was lower than that of OPCC, which was attributed to the fact that the alkali-activated fly ash paste exhibited lower fracture energy than OPC paste. Furthermore, it can be seen from Fig. 10 that the CEB-FIP model overestimates the fracture energy of alkali-activated fly ash concrete, but predicts reasonably well the fracture energy of OPCC, as obtained by Pan et al. [72]. Fig. 10 also shows that the fracture energy of alkali-activated fly ash concrete obtained by Sarker et al. [73] was generally comparable to that of OPCC given similar compressive strength. In addition, the predictions of fracture energies of the Bazant and Becq-Giraduon model were much higher than those of the CEB-FIP model, and much closer to the test results obtained by Sarker et al. [73]. 


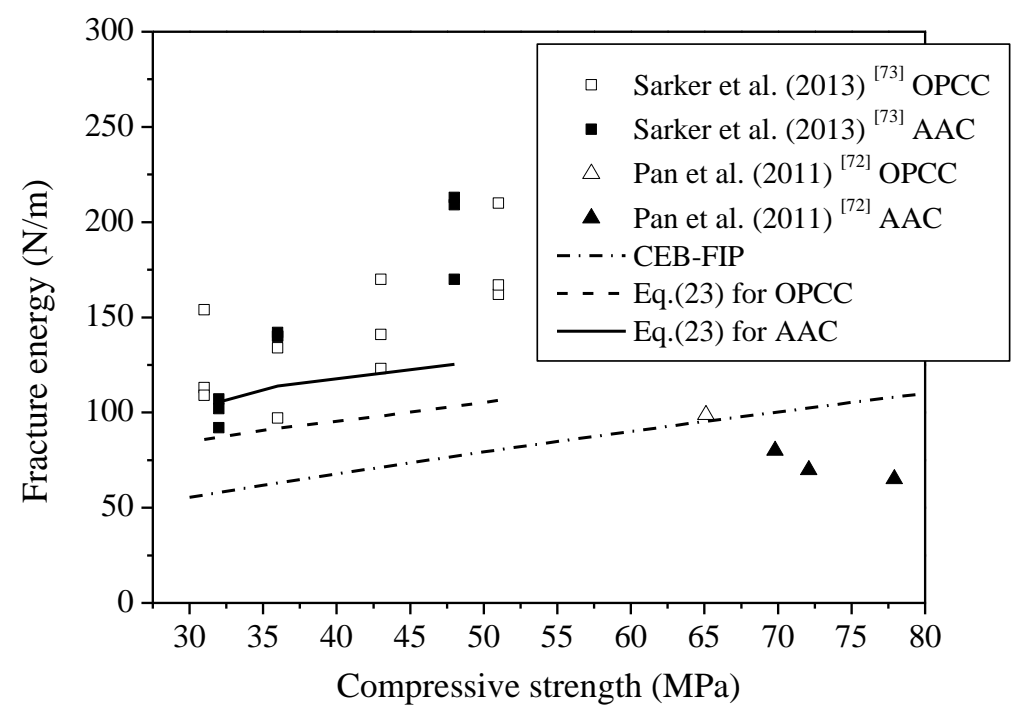

Fig. 10 Relationship between compressive strength and fracture energy

Based on results of these two experimental program as shown in Fig.10, it seems that the brittleness of alkali-activated fly ash concrete and its OPCC counterpart are different. However, whether other types of AACs exhibit different fracture behavior from that of OPCC and whether the fracture energy of AAC can be estimated by the formula proposed for OPCC still require further study.

\subsection{Bond Mechanism of Steel Reinforcement in Alkali-Activated Concrete}

Reinforced concrete functions effectively as a composite material because the steel reinforcement is well bonded to the surrounding concrete [71] and this allows the forces to transfer from the concrete to the steel reinforcement. It is generally known that the bond strength is governed by the strength of the concrete, the thickness of the concrete cover surrounding the steel bar, and the geometry of the steel bar. The bond stress-slip relationship of the deformed reinforcement in OPCC can be predicted by the CEB-FIP model as follows:

$$
\tau_{b}=2.0 \sqrt{f_{c}^{\prime}}
$$




$$
\left\{\begin{array}{lr}
\tau^{\prime}=\tau_{b}\left(s / s_{1}\right)^{\alpha} & \text { for } s \leq s_{1} \\
\tau^{\prime}=\tau_{b} & \text { for } s_{1}<s \leq s_{2} \\
\tau^{\prime}=\tau_{b}-\left(s-s_{2}\right)\left(\tau_{b}-\tau_{f}\right) /\left(s_{3}-s_{2}\right) & \text { for } s_{2}<s \leq s_{3} \\
\tau^{\prime}=\tau_{f}=0.3 \sqrt{f_{c}^{\prime}} & \text { for } \mathrm{s} \geq s_{3}
\end{array}\right.
$$

where $\alpha=0.4, s_{1}=s_{2}=0.6 \mathrm{~mm}$, and $s_{3}=1.0 \mathrm{~mm}$ for the ribbed reinforced bars in unconfined concrete.

Almost all of the experimental results have suggested that the AAC bonds better with steel reinforcement than OPCC [45, 56-66]. Most of the researchers have attributed ACC's high bond strength to its homogenous micro-structure. Morphological studies have shown that the ITZ between the aggregate and the alkali-activated matrix is denser and more homogenous than in OPCC [67, 69] and there is no obvious difference between the micro-hardness of the ITZ and bulk matrix [70]. The stronger ITZ results in the higher splitting tensile strength and higher bond strength of AAC. Fernández-Jiménez et al. [45] conducted pull-out tests and found that steel reinforcement may break before slipping, but also demonstrated that the alkali-activated fly ash concrete performed excellently in terms of bond. Sarker [65] focused on the effects of compressive strength and the thickness of the concrete cover on the bond behavior of steel reinforcement in alkali-activated fly ash concrete. He found that the alkali-activated fly ash concrete and OPCC specimens all failed due to splitting of the concrete in the pull-out tests, but generally the alkali-activated fly ash concrete had higher bond strengths than OPCC. Castel and Foster [64] stated that the bond strength of alkali-activated slag-fly ash concrete with steel reinforcement was slightly higher, about $10 \%$ on average, than its OPCC counterpart given an equivalent compressive strength. The steel reinforcement in alkali-activated slag-fly ash concrete has bond stress-slip curves similar to those of OPCC, as shown in Fig.11. Yang et al. [56] studied the bond behavior of steel reinforcement in AASC. The obtained bond stress-slip curves, depicted in Fig.11, showed that the descending branches of all of 
the AAC and OPCC specimens were higher than those predicted by the CEB-FIP model. In addition, the amount of bar slip at the peak stress in the results of Yang et al. [56] was slightly lower than the value of $0.6 \mathrm{~mm}$ specified in the CEB-FIP model; this value was close to the $0.6 \mathrm{~mm}$ found by Castel and Foster [64].

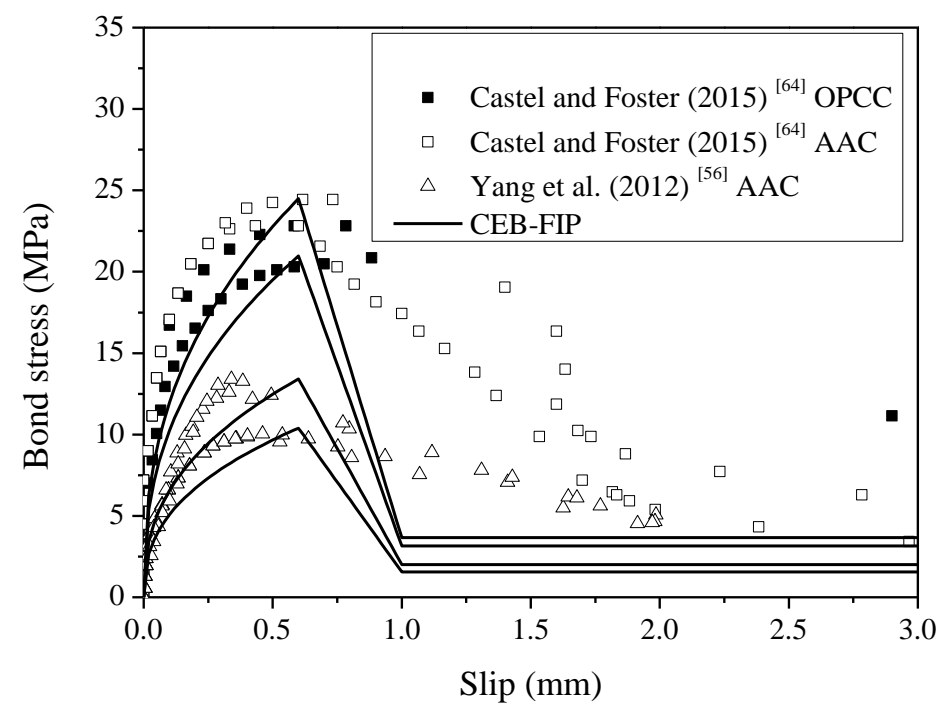

Fig.11 Bond stress-slip curves

The relationships between bond strength and the corresponding compressive strength are summarized in Fig. 12. The relationships suggested by the CEB-FIP model (Eq. (24)) are also presented in Fig. 12, which shows that the CEB-FIP model fits reasonably well with the test results obtained by Yang et al. [56], but generally overestimates the test results obtained by Sofi et al. [41] and underestimates Sarker's [65] test results. 


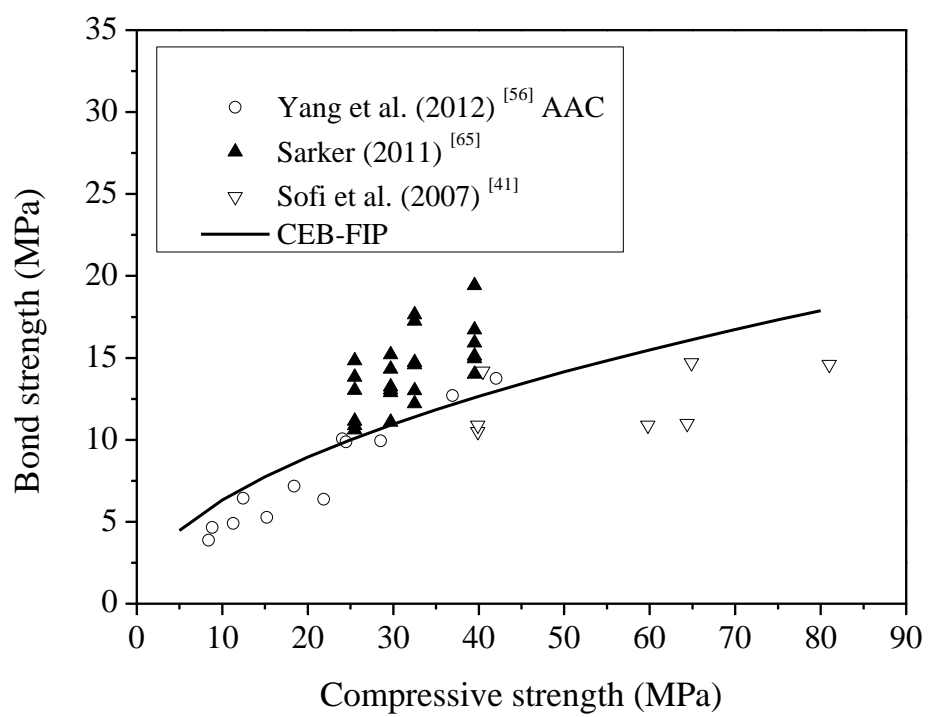

Fig. 12 Relationship between bond strength and compressive strength

\section{Dynamic Mechanical Properties of Alkali-Activated Concrete}

The strain rate effect on materials, induced by high-amplitude short-duration loads, is identified as an important dynamic property. Compared to the limited research on the strain rate effect of AAC, extensive studies have been conducted on OPCC. The strain rate effect of OPCC can be evaluated by the dynamic increase factor (DIF), which is equal to the ratio of dynamic strength/strain to static strength/strain, and can be predicted by the CEB-FIP model as follows:

$$
\begin{aligned}
& \begin{cases}D I F_{f_{c}}=\sigma_{d} / \sigma_{s}=\left(\dot{\varepsilon}_{d} / \dot{\varepsilon}_{s}\right)^{1.026 \alpha_{s}} & \text { for } \dot{\varepsilon}_{d} \leq 30 \mathrm{~s}^{-1} \\
D I F_{f_{c}}=\sigma_{d} / \sigma_{s}=\gamma\left(\dot{\varepsilon}_{d} / \dot{\varepsilon}_{s}\right)^{\frac{1}{3}} & \text { for } \dot{\varepsilon}_{d}>30 \mathrm{~s}^{-1}\end{cases} \\
& D I F_{\varepsilon_{c}}=\varepsilon_{c d} / \varepsilon_{c s}=\left(\dot{\varepsilon}_{d} / \dot{\varepsilon}_{s}\right)^{0.02}
\end{aligned}
$$

where $\dot{\varepsilon}_{d}$ is the strain rate $\left(\mathrm{s}^{-1}\right), \quad \dot{\varepsilon}_{s}=30 \times 10^{-6} \mathrm{~s}^{-1}, \quad \alpha_{s}=\left(5+9 f_{c m} / f_{c m 0}\right)^{-1}$, $\log \gamma=6.156 \alpha_{s}-2, f_{c m}$ is the compressive strength (MPa), and $f_{c m 0}$ is $10 \mathrm{MPa}$.

The results obtained by Feng et al. [76], Luo et al. [77, 79], Gao et al. [78], and Khandelwal et al. [80] demonstrated that AAC was a strain-rate sensitive material and 
that DIF increased with the strain rate. The cracks in AAC subjected to quasi-static and low strain rate loads propagated mainly along the ITZ between the matrix and the coarse aggregates. In contrast, the specimens were pulverized into small pieces when subjected to high strain rate loading and the cracks occurred in both the aggregates and the ITZ. All of these phenomena are similar to those that occur in OPCC. Luo et al. [77, 79] used the Split Hopkinson Pressure Bar (SHPB) to test the dynamic properties of alkali-activated slag-fly ash concrete under compression at high strain rate and stated that the alkali-activated slag-fly ash concrete had higher strain rate sensitivity than OPCC, perhaps due to the three-dimensional hydration products formed in the alkali-activated slag-fly ash concrete, which can effectively transfer the stress from the loading position to the inner part of the specimen. In addition, the peak strain went up with the strain rate in the beginning, but decreased after the strain rate reached the threshold, because when the strain rate is below the threshold, the strain rate damage softening plays a critical role, whereas the strain rate hardening effect becomes the primary influential factor when the strain rate exceeds a threshold. Feng et al. [76] conducted SHPB tests on the alkali-activated fly ash concrete activated by different alkaline activators and stated that under high strain rate loading, the $D I F_{f_{c}}$ of alkali-activated fly ash concrete was in agreement with the CEB-FIP model prediction. However, the CEB-FIP model underestimated the DIF $F_{\varepsilon_{c}}$ of alkali-activated fly ash concrete at a high strain rate. Gao et al. [78] calculated the impact toughness of alkali-activated slag concrete and illustrated that the alkali-activated slag concrete specimens still possessed a good ability to absorb energy after the peak load.

\section{High-temperature Resistance of Alkali-Activated Concrete}

The strength deterioration of OPCC due to heating is the result of physical and chemical mechanisms [81]. The thermal incompatibility between coarse aggregates and mortar matrix leads to internal micro-stress and micro-cracking. In addition, the 
decomposition of calcium hydroxide in OPCC occurs at temperatures exceeding $400^{\circ} \mathrm{C}$, both causing serious strength loss [82]. Further, high strength OPCC is prone to spalling when the temperature rises further [83, 84]. Alkali-activated cements are generally believed to have better high-temperature resistance than OPC [9]. As high-temperature performance is a fundamental property of concrete, the performances of AAC exposed to elevated temperatures and the high-temperature resistance of alkali-activated paste and mortar are also examined in this paper.

Several studies have reported the high-temperature resistance of alkali-activated slag (AAS) mortar [85-87]. The strength performance of AAS mortar at temperatures exceeding $400^{\circ} \mathrm{C}$ was similar to that of OPC mortar. The dehydration of C-S-H gel is the reason for the loss of strength of AAS mortars [85]. The residual strength of AAS mortars at $800^{\circ} \mathrm{C}$ was in the range of $18-35 \%$ of the initial strength [85-87]. Guerrier et al. [88] reported that the strength performance of AASC in the temperature range of $400-800^{\circ} \mathrm{C}$ was similar to that of OPCC and the residual compressive strength was $10 \%$ of the initial strength when exposed to $800^{\circ} \mathrm{C}$. They attributed the strength loss of AASC mainly to thermal incompatibility because at elevated temperatures the AAS binders shrank while the basalt aggregates expanded.

Guerrier et al. [89] further studied the mechanical behavior of alkali-activated slag-fly ash pastes exposed to elevated temperature and found that the specimens with low initial strengths (i.e., $<7.6 \mathrm{MPa}$ ) experienced a residual strength increase of up to $90 \%$ after exposure to $800^{\circ} \mathrm{C}$. This was caused by the combination of further hydration of the unreacted binders and sintering. In contrast, specimens with high initial strengths had a residual strength loss of up to $90 \%$ after exposure to $800^{\circ} \mathrm{C}$.

Fernández et al. [92, 93] studied the high-temperature performances of alkali-activated fly ash paste and found that a pseudo-viscous phase was generated at around $600-700^{\circ} \mathrm{C}$. As shown in Fig. 13, the minimum residual strength was also observed in this temperature range, which is consistent with other studies [94]. The 
formation of this pseudo-viscous phase can explain the decline of strength at this temperature range, whereas its subsequent recrystallization into new phases like nepheline, albite, and gehlenite is responsible for the high residual strength at higher temperatures. In addition, as shown in Fig. 13, the alkali-activated fly ash paste performed better at elevated temperatures than the OPC paste. It is known that the C-S-H gel in OPC starts to decompose at $105^{\circ} \mathrm{C}$ and the dehydroxylation of calcium hydroxide occurs at between $400-500^{\circ} \mathrm{C}$. Both of these phenomena result in the reduction of strength of OPC paste. As there is almost no calcium hydroxide or $\mathrm{C}-\mathrm{S}-\mathrm{H}$ gel in the alkali-activated fly ash paste, the further hydration of the unreacted binders and recrystallization of the molten phases at elevated temperatures could explain its better residual strength. In addition, as the initial compressive strength of the alkali-activated fly ash pastes increased, the residual compressive strength decreased after exposure to elevated temperatures [90, 91]. Kong and Sanjayan [95] found that small specimens of alkali-activated fly ash concrete with aggregate sizes larger than $10 \mathrm{~mm}$ resulted in good strength performances at elevated temperatures; the strength loss was up to $65 \%$ after exposure to $800^{\circ} \mathrm{C}$, which was mainly attributed to thermal incompatibility [96]. More recently, Talha et al. [97] reported that between $20-200^{\circ} \mathrm{C}$ all the tested alkali-activated fly ash concrete samples underwent a decrease in strength; however, a moderate to significant strength gain was found between $200-400^{\circ} \mathrm{C}$; then, all samples had a significant strength loss after exposure to $800^{\circ} \mathrm{C}$. 


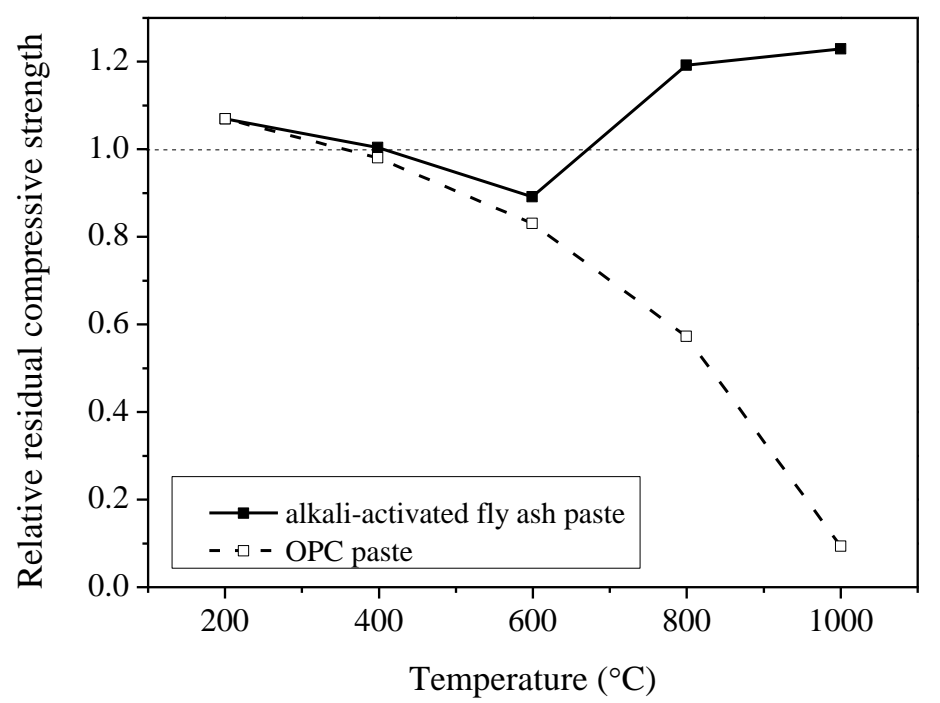

Fig. 13 Residual compressive strength of OPC and alkali-activated fly ash pastes [93]

\section{Conclusions}

This paper provides a comprehensive review of research on the fundamental mechanical properties of AAC. Based on this review, the following conclusions can be drawn.

1. Alkali-activated slag concrete has high early age compressive strength and rapid strength development, whereas alkali-activated fly ash concrete generally needs heat curing to obtain a reasonable early age strength. A combination of slag and fly ash allows AAC to achieve a reasonable early age compressive strength without heat curing.

2. Although most of the existing studies reported that the elastic modulus of AAC is in the same range of 10-40 $\mathrm{GPa}$ as OPCC, the discrepancies in the results are significant. The elastic modulus of AASC is close to that predicted by codes of practice for OPCC, but the elastic modulus of alkali-activated fly ash concrete and alkali-activated slag-fly ash concrete are generally overestimated by the codes of practice for OPCC, because the intrinsic Young's modulus of N-A-S-H gels formed in alkali-activated fly ash is around 17-18 GPa, which is much lower than the C-S-H gel formed in alkali-activated slag. Due to these inherently 
different material compositions, none of the existing models can accurately predict the relationship between the elastic modulus and corresponding compressive strength of AAC.

3. The CEB-FIP model generally overestimates the ascending branch of the stress-strain curve of AASC under uniaxial compression, whereas the descending branches obtained by different researchers are inconsistent. Similarly, the stress-strain relationship of alkali-activated fly ash concrete cannot be predicted by the CEB-FIP model for most of the cases.

4. No firm conclusions can be made about the range of the Poisson's ratio of AAC. However, most of the researchers reported that the Poisson's ratio of alkali-activated fly ash concrete is lower than the average value of the Poisson's ratio of OPCC (i.e., $\approx 0.18$ ).

5. The splitting tensile strengths of AAC are close to those predicted by the ACI building code 318 or Eurocode 2. Based on the limited available test results, two equations with similar accuracy have been proposed that can accurately predict the relationship between the splitting tensile strength and the corresponding compressive strength of AAC. However, more test results are needed to validate the proposed models.

6. Existing fracture tests showed that alkali-activated fly ash concrete and its OPCC counterpart have different brittleness. However, due to the limited test results, there is no clear difference in the fracture energy of alkali-activated fly ash concretes and OPCCs with similar compressive strengths.

7. All of the test results indicated that AAC bonds better with steel reinforcement than OPCC. The bond stress-slip curves of AAC and OPCC are similar. The CEB-FIB model provides a reasonable prediction of the bond strength of AAC with steel reinforcement. 
8. AAC is a strain-rate sensitive material whose failure modes under impact load are similar to those of OPCC.

9. Alkali-activated fly ash paste always exhibits better high-temperature resistance than OPC paste. The residual strength of alkali-activated fly ash paste after exposure to elevated temperatures rises if the initial compressive strength is low due to the further hydration of the unreacted binders and recrystallization of the molten phases. However, the alkali-activated slag concrete always has a strength performance similar to its OPCC counterpart in the temperature range of $400-800^{\circ} \mathrm{C}$. The strength loss is mainly attributed to thermal incompatibility.

10. Considering the large variations in the mechanical properties of AAC systems as discussed in the paper, there is an urgent need to establish a clear and unified index to take into account the diversity of AAC mix design and link it to the mechanical properties.

\section{Acknowledgements}

The authors are grateful for the financial support received from the National Science Foundation of China (NSFC) Project Nos. 51638008 and Construction Industry Council Fund (Project code: K-ZJK2). They are also grateful for a PhD studentship awarded to the first author by The Hong Kong Polytechnic University.

\section{References}

[1] Gartner, E. (2004). Industrially interesting approaches to "low- $\mathrm{CO}_{2}$ " cements. Cement and Concrete Research, 34(9), 1489-1498.

[2] Alonzo, O., Barringer, W. L., Barton, S. G., Bell, L. W., Bennett, J. E., Boyle, M., ... \& Dixon, D. E. (1993). Guide for selecting proportions for high-strength concrete with Portland cement and fly ash. ACI Materials Journal, 90(3), 272-283

[3] Ramezanianpour, A. A., \& Malhotra, V. M. (1995). Effect of curing on the compressive strength, resistance to chloride-ion penetration and porosity of concretes incorporating slag, 
fly ash or silica fume. Cement and Concrete Composites, 17(2), 125-133.

[4] Osborne, G. J. (1999). Durability of Portland blast-furnace slag cement concrete. Cement and Concrete Composites, 21(1), 11-21.

[5] Jau, W. C., \& Tsay, D. S. (1998). A study of the basic engineering properties of slag cement concrete and its resistance to seawater corrosion. Cement and Concrete Research, 28(10), 1363-1371.

[6] Malhotra, V. M., \& Mehta, P. K. (2002). High-performance, high-volume fly ash concrete. Concrete International, 24(7), 30-34.

[7] Bilodeau, A., \& Malhotra, V. M. (2000). High-volume fly ash system: Concrete solution for sustainable development. ACI Materials Journal, 97(1).

[8] Davidovits, J. (1991). Geopolymers. Journal of Thermal Analysis, 37(8), 1633-1656.

[9] Duxson, P., Provis, J. L., Lukey, G. C., \& Van Deventer, J. S. (2007). The role of inorganic polymer technology in the development of 'green concrete'. Cement and Concrete Research, 37(12), 1590-1597.

[10] Provis, J. L., \& Van Deventer, J. S. J. (Eds.). (2009). Geopolymers: Structures, processing, properties and industrial applications. CRC Press.,

[11] Wang, S. D., \& Scrivener, K. L. (1995). Hydration products of alkali activated slag cement. Cement and Concrete Research, 25(3), 561-571.

[12] Shi, C., \& Day, R. L. (1996). Selectivity of alkaline activators for the activation of slags. Cement, Concrete and Aggregates, 18(1), 8-14.

[13] Fernández-Jiménez, A., \& Palomo, A. (2005). Composition and microstructure of alkali activated fly ash binder: Effect of the activator. Cement and Concrete Research, 35(10), 1984-1992.

[14] Palomo, A., Grutzeck, M. W., \& Blanco, M. T. (1999). Alkali-activated fly ashes: A cement for the future. Cement and Concrete Research, 29(8), 1323-1329.

[15] Criado, M., Aperador, W., \& Sobrados, I. (2016). Microstructural and Mechanical Properties of Alkali Activated Colombian Raw Materials.Materials, 9(3), 158.

[16] Tennakoon, C., Sagoe-Crentsil, K., San Nicolas, R., \& Sanjayan, J. G. (2015). Characteristics of Australian brown coal fly ash blended geopolymers. Construction and Building Materials, 101, 396-409.

[17] Shi, C., Roy, D., \& Krivenko, P. (2006). Alkali-activated Cements and Concretes. CRC press.

[18] Palacios, M., \& Puertas, F. (2005). Effect of superplasticizer and shrinkage-reducing admixtures on alkali-activated slag pastes and mortars. Cement and Concrete Research, 35(7), 1358-1367. 
[19] Palacios, M., \& Puertas, F. (2007). Effect of shrinkage-reducing admixtures on the properties of alkali-activated slag mortars and pastes. Cement and Concrete Research, 37(5), 691-702.

[20] Aydın, S., \& Baradan, B. (2013). The effect of fiber properties on high performance alkali-activated slag/silica fume mortars. Composites Part B: Engineering, 45(1), 63-69.

[21] Puertas, F., Amat, T., Fernández-Jiménez, A., \& Vázquez, T. (2003). Mechanical and durable behaviour of alkaline cement mortars reinforced with polypropylene fibres. Cement and Concrete Research, 33(12), 2031-2036.

[22] Vilaplana, J. L., Baeza, F. J., Galao, O., Alcocel, E. G., Zornoza, E., \& Garcés, P. (2016). Mechanical properties of alkali activated blast furnace slag pastes reinforced with carbon fibers. Construction and Building Materials,116, 63-71.

[23] Pu, X. C., Gan, C. C., Wang, S. D., \& Yang, C. H. (1988). Summary reports of research on alkali-activated slag cement and concrete. Chongqing Institute of Architecture and Engineering, Chongqing, 1-6. (in Chinese)

[24] Bernal, S. A., de Gutiérrez, R. M., Pedraza, A. L., Provis, J. L., Rodriguez, E. D., \& Delvasto, S. (2011). Effect of binder content on the performance of alkali-activated slag concretes. Cement and Concrete Research, 41(1), 1-8.

[25] Bakharev, T., Sanjayan, J. G., \& Cheng, Y. B. (2000). Effect of admixtures on properties of alkali-activated slag concrete. Cement and Concrete Research, 30(9), 1367-1374.

[26] Bakharev, T., Sanjayan, J. G., \& Cheng, Y. B. (1999). Effect of elevated temperature curing on properties of alkali-activated slag concrete. Cement and Concrete Research, 29(10), 1619-1625.

[27] Collins, F., \& Sanjayan, J. G. (2001). Microcracking and strength development of alkali activated slag concrete. Cement and Concrete Composites, 23(4), 345-352.

[28] Chi, M. (2012). Effects of dosage of alkali-activated solution and curing conditions on the properties and durability of alkali-activated slag concrete. Construction and Building Materials, 35, 240-245.

[29] Bakharev, T. (2005). Geopolymeric materials prepared using Class F fly ash and elevated temperature curing. Cement and Concrete Research, 35(6), 1224-1232.

[30] Jiang, W., \& Roy, D. M. (1992). Hydrothermal processing of new fly ash cement. American Ceramic Society Bulletin;(United States), 71(4), 642-647.

[31] Hardjito, D. (2005). Studies of fly ash-based geopolymer concrete. Curtin University of Technology.

[32] Okoye, F. N., Durgaprasad, J., \& Singh, N. B. (2015). Mechanical properties of alkali activated flyash/Kaolin based geopolymer concrete. Construction and Building Materials, 98 , 685-691. 
[33] Williamson, T., \& Juenger, M. C. (2016). The role of activating solution concentration on alkali-silica reaction in alkali-activated fly ash concrete. Cement and Concrete Research, 83, 124-130.

[34] Rashad, A. M. (2013). Properties of alkali-activated fly ash concrete blended with slag. Iran J Mater Sci Eng, 10(1), 57-64.

[35] Nath, P., \& Sarker, P. K. (2014). Effect of GGBFS on setting, workability and early strength properties of fly ash geopolymer concrete cured in ambient condition. Construction and Building Materials, 66, 163-171.

[36] Ryu, G. S., Lee, Y. B., Koh, K. T., \& Chung, Y. S. (2013). The mechanical properties of fly ash-based geopolymer concrete with alkaline activators. Construction and Building Materials, 47, 409-418.

[37] Collins, F. G., \& Sanjayan, J. G. (1999). Workability and mechanical properties of alkali activated slag concrete. Cement and Concrete Research, 29(3), 455-458.

[38] Chindaprasirt, P., Chareerat, T., \& Sirivivatnanon, V. (2007). Workability and strength of coarse high calcium fly ash geopolymer. Cement and Concrete Composites, 29(3), 224-229.

[39] Collins, F., \& Sanjayan, J. G. (1998). Early age strength and workability of slag pastes activated by $\mathrm{NaOH}$ and $\mathrm{Na} 2 \mathrm{CO} 3$. Cement and Concrete Research, 28(5), 655-664.

[40] Douglas, E., Bilodeau, A., \& Malhotra, V. M. (1992). Properties and durability of alkali-activated slag concrete. Materials Journal, 89(5), 509-516.

[41] Sofi, M., Van Deventer, J. S. J., Mendis, P. A., \& Lukey, G. C. (2007). Engineering properties of inorganic polymer concretes (IPCs). Cement and Concrete Research, 37(2), 251-257.

[42] Duxson, P., Provis, J. L., Lukey, G. C., Mallicoat, S. W., Kriven, W. M., \& Van Deventer, J. S. (2005). Understanding the relationship between geopolymer composition, microstructure and mechanical properties. Colloids and Surfaces A: Physicochemical and Engineering Aspects, 269(1), 47-58.

[43] Thomas, R. J., \& Peethamparan, S. (2015). Alkali-activated concrete: Engineering properties and stress-strain behavior. Construction and Building Materials, 93, 49-56.

[44] Lee, N. K., \& Lee, H. K. (2013). Setting and mechanical properties of alkali-activated fly ash/slag concrete manufactured at room temperature. Construction and Building Materials, 47, 1201-1209.

[45] Fernandez-Jimenez, A. M., Palomo, A., \& Lopez-Hombrados, C. (2006). Engineering properties of alkali-activated fly ash concrete. ACI Materials Journal, 103(2), 106-112.

[46] Standard, A. (2002). AS 3600-Concrete structures. Standards Australia International.

[47] ACI Committee. (2005). Building code requirements for structural concrete (ACI 318-05) and commentary (ACI 318R-05). American Concrete Institute. 
[48] Code, C. F. M. (1993). Comite Euro-International du Beton. Bulletin d'Information, 213, 214.

[49] EN, B. (2004). 1-2: 2004 Eurocode 2: Design of concrete structures-Part 1-2: General rules-Structural fire design. European Standards, London.

[50] Joseph, B., \& Mathew, G. (2012). Influence of aggregate content on the behavior of fly ash based geopolymer concrete. Scientia Iranica, 19(5), 1188-1194.

[51] Weng, L., \& Sagoe-Crentsil, K. (2007). Dissolution processes, hydrolysis and condensation reactions during geopolymer synthesis: Part I- Low Si/Al ratio systems. Journal of Materials Science, 42(9), 2997-3006.

[52] Duxson, P., Lukey, G. C., Separovic, F. \& Van Deventer, J. S. J. (2005). Effect of alkali cations on aluminum incorporation in geopolymeric gels. Industrial \& Engineering Chemistry Research, 44(4), 832-839.

[53] Guo, X., Shi, H., \& Dick, W. A. (2010). Compressive strength and microstructural characteristics of class $\mathrm{C}$ fly ash geopolymer. Cement and Concrete Composites, 32(2), 142-147.

[54] Puertas, F., Palacios, M., Manzano, H., Dolado, J. S., Rico, A., \& Rodríguez, J. (2011). A model for the CASH gel formed in alkali-activated slag cements. Journal of the European Ceramic Society, 31(12), 2043-2056.

[55] Němeček, J., Šmilauer, V., \& Kopecký, L. (2011). Nanoindentation characteristics of alkali-activated aluminosilicate materials. Cement and Concrete Composites, 33(2), 163-170.

[56] Yang, K. H., Cho, A. R., \& Song, J. K. (2012). Effect of water-binder ratio on the mechanical properties of calcium hydroxide-based alkali-activated slag concrete. Construction and Building Materials, 29, 504-511.

[57] Diaz, E. I., \& Allouche, E. N. (2010, April). Recycling of fly ash into geopolymer concrete: Creation of a database. In Green Technologies Conference, 2010 IEEE (pp. 1-7). IEEE.

[58] Duxson, P. S. W. M., Mallicoat, S. W., Lukey, G. C., Kriven, W. M., \& Van Deventer, J. S. J. (2007). The effect of alkali and Si/Al ratio on the development of mechanical properties of metakaolin-based geopolymers. Colloids and Surfaces A: Physicochemical and Engineering Aspects, 292(1), 8-20.

[59] Warner, R. F., Rangan, B. V., Hall, A. S., \& Faulkes, K. A. (1998). Concrete Structures, LONGMAN.

[60] Bondar, D., Lynsdale, C. J., Milestone, N. B., Hassani, N., \& Ramezanianpour, A. A. (2011). Engineering properties of alkali-activated natural pozzolan concrete. ACI Materials Journal, 108(1), 64-72.

[61] Neville, A. M. (1995). Properties of concrete. John Wiley \& Sons.

[62] Atiş, C. D., Bilim, C., Çelik, Ö., \& Karahan, O. (2009). Influence of activator on the strength 
and drying shrinkage of alkali-activated slag mortar. Construction and Building Materials, 23(1), 548-555.

[63] Collins, M. P., Mitchell, D., \& MacGregor, J. G. (1993). Structural design considerations for high-strength concrete. Concrete International, 15(5), 27-34.

[64] Castel, A., \& Foster, S. J. (2015). Bond strength between blended slag and Class F fly ash geopolymer concrete with steel reinforcement. Cement and Concrete Research, 72, 48-53.

[65] Sarker, P. K. (2011). Bond strength of reinforcing steel embedded in fly ash-based geopolymer concrete. Materials and Structures, 44(5), 1021-1030.

[66] Songpiriyakij, S., Pulngern, T., Pungpremtrakul, P., \& Jaturapitakkul, C. (2011). Anchorage of steel bars in concrete by geopolymer paste. Materials \& Design, 32(5), 3021-3028.

[67] Shi, C., \& Xie, P. (1998). Interface between cement paste and quartz sand in alkali-activated slag mortars. Cement and Concrete Research, 28(6), 887-896.

[68] San Nicolas, R., \& Provis, J. L. (2012). Interfacial transition zone in alkali-activated slag concrete. In Twelfth International Conference on Recent Advances in Concrete Technology and Sustainability Issues, ACI SP 289, Supplementary Papers CD-ROM. American Concrete Institute, Prague, Czech Republic.

[69] Lee, W. K. W., \& Van Deventer, J. S. J. (2004). The interface between natural siliceous aggregates and geopolymers. Cement and Concrete Research, 34(2), 195-206.

[70] Wang, H., \& Gillott, J. E. (1991). Mechanism of alkali-silica reaction and the significance of calcium hydroxide. Cement and Concrete Research, 21(4), 647-654.

[71] Park, R., \& Paulay, T. (1975). Reinforced Concrete Sructures. John Wiley \& Sons.

[72] Pan, Z., Sanjayan, J. G., \& Rangan, B. V. (2011). Fracture properties of geopolymer paste and concrete. Magazine of Concrete Research, 63(10), 763-771.

[73] Sarker, P. K., Haque, R., \& Ramgolam, K. V. (2013). Fracture behaviour of heat cured fly ash based geopolymer concrete. Materials \& Design, 44, 580-586.

[74] Bažant, Z. P., \& Becq-Giraudon, E. (2002). Statistical prediction of fracture parameters of concrete and implications for choice of testing standard. Cement and Concrete Research, 32(4), 529-556.

[75] RILEM, FMC1. (1994). Determination of the fracture energy of mortar and concrete by means of three-point bend tests on notched beams, RILEM Technical Recommendations for the Testing and Use of Construction Materials, E and FN SPON, London, pp. 99-101.

[76] Feng, K. N., Ruan, D., Pan, Z., Collins, F., Bai, Y., Wang, C. M., \& Duan, W. H. (2015). Mechanical behavior of geopolymer concrete subjected to high strain rate compressive loadings. Materials and Structures, 48(3), 671-681.

[77] Luo, X., Xu, J. Y., Bai, E. L., \& Li, W. (2013). Research on the dynamic compressive test of 
highly fluidized geopolymer concrete. Construction and Building Materials, 48, 166-172.

[78] Gao, Y., Xu, J., Bai, E., Luo, X., Zhu, J., \& Nie, L. (2015). Static and dynamic mechanical properties of high early strength alkali activated slag concrete. Ceramics International, 41(10), 12901-12909.

[79] Xin, L., Jin-yu, X., Weimin, L., \& Erlei, B. (2014). Effect of alkali-activator types on the dynamic compressive deformation behavior of geopolymer concrete. Materials Letters, 124, 310-312.

[80] Khandelwal, M., Ranjith, P. G., Pan, Z., \& Sanjayan, J. G. (2013). Effect of strain rate on strength properties of low-calcium fly-ash-based geopolymer mortar under dry condition. Arabian Journal of Geosciences, 6(7), 2383-2389.

[81] Lea, F. C. (1922). The resistance to fire of concrete and reinforced concrete. Journal of the Society of Chemical Industry, 41(18), 395R-396R.

[82] Bazant, Z. P., \& Kaplan, M. F. (1996). Concrete at high temperatures: material properties and mathematical models. Longman Group Limited.

[83] Hertz, K. D. (2003). Limits of spalling of fire-exposed concrete. Fire Safety Journal, 38(2), 103-116.

[84] Phan, L. T., Lawson, J. R., \& Davis, F. L. (2001). Effects of elevated temperature exposure on heating characteristics, spalling, and residual properties of high performance concrete. Materials and Structures, 34(2), 83-91.

[85] Mejía de Gutierrez, R., Maldonado, J., \& Gutiérrez, C. (2004). Performance of alkaline activated slag at high temperatures. Materiales De Construccion, 54(276), 87-92.

[86] Zuda, L., Rovnaník, P., Bayer, P., \& Černý, R. (2007). Thermal properties of alkali-activated slag subjected to high temperatures. Journal of Building Physics, 30(4), 337-350.

[87] Zuda, L., Pavlík, Z., Rovnaníková, P., Bayer, P., \& Černý, R. (2006). Properties of alkali activated aluminosilicate material after thermal load. International Journal of Thermophysics, 27(4), 1250-1263.

[88] Guerrieri, M., Sanjayan, J., \& Collins, F. (2009). Residual compressive behavior of alkali activated concrete exposed to elevated temperatures. Fire and Materials, 33(1), 51-62.

[89] Guerrieri, M., \& Sanjayan, J. G. (2010). Behavior of combined fly ash/slag - based geopolymers when exposed to high temperatures. Fire and Materials, 34(4), 163-175.

[90] Bakharev, T. (2006). Thermal behaviour of geopolymers prepared using class F fly ash and elevated temperature curing. Cement and Concrete Research, 36(6), 1134-1147.

[91] Rashad, A. M., \& Zeedan, S. R. (2011). The effect of activator concentration on the residual strength of alkali-activated fly ash pastes subjected to thermal load. Construction and Building Materials, 25(7), 3098-3107. 
[92] Fernández - Jiménez, A., Palomo, A., Pastor, J. Y., \& Martin, A. (2008). New cementitious materials based on alkali - activated fly ash: Performance at high temperatures. Journal of the American Ceramic Society, 91(10), 3308-3314.

[93] Fernández - Jiménez, A., Pastor, J. Y., Martín, A., \& Palomo, A. (2010). High - temperature resistance in alkali - activated cement. Journal of the American Ceramic Society, 93(10), 3411-3417.

[94] Škvára, F., Jílek, T., \& Kopecký, L. (2005). Geopolymer materials based on fly ash. Ceram.-Silik, 49(3), 195-204.

[95] Kong, D. L., \& Sanjayan, J. G. (2010). Effect of elevated temperatures on geopolymer paste, mortar and concrete. Cement and Concrete Research, 40(2), 334-339.

[96] Kong, D. L., \& Sanjayan, J. G. (2008). Damage behavior of geopolymer composites exposed to elevated temperatures. Cement and Concrete Composites, 30(10), 986-991.

[97] Talha Junaid, M., Kayali, O., \& Khennane, A. (2017). Response of alkali activated low calcium fly-ash based geopolymer concrete under compressive load at elevated temperatures. Materials and Structures, 50(1), 1-10. 